AD

\title{
CURRENT AND FUTURE LOAD BEARING EQUIPMENT OF THE UNITED STATES MARINES: AN ONLINE SURVEY
}

\author{
by \\ Justine Federici \\ and \\ Larry L. Lesher* \\ *GEO-CENTERS, INC. \\ Natick, MA 01760
}

July 2003

Final Report

April 2002 - September 2002

Approved for public release; distribution is unlimited

U.S. Army Soldier and Biological Chemical Command

Soldier Systems Center

Natick, Massachusetts 01760-5020 


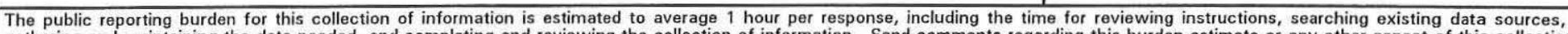

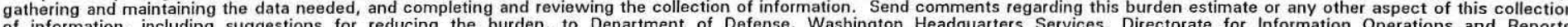

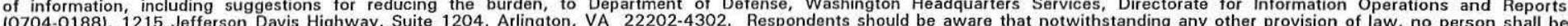
(0704-0188), 1215 Jefferson Davis Highway, Suite 1204, Arlington, VA 22202-4302. Respondents should be aware that notwithst

PLEASE DO NOT RETURN YOUR FORM TO THE ABOVE ADDRESS.
1. REPORT DATE (DD-MM-YYYY)
2. REPORT TYPE
03-07-03
Final
3. DATES COVERED (From - To)
April 2002-September 2002

4. TITLE AND SUBTITLE

CURRENT AND FUTURE LOAD BEARING EQUIPMENT OF THE

UNITED STATES MARINES: AN ONLINE SURVEY

5b. GRANT NUMBER

5c. PROGRAM ELEMENT NUMBER

654713

6. AUTHOR(S)
Justine Federici and Larry L. Lesher *

\section{5d. PROJECT NUMBER}

5e. TASK NUMBER

5f. WORK UNIT NUMBER

7. PERFORMING ORGANIZATION NAME(S) AND ADDRESS(ES)

U.S. Army Soldier and Biological Chemical Command

Natick Soldier Systems Center

ATTN: Justine Federici, AMSSB-RSS-P (N)

Natick, MA 01760-5020

9. SPONSORING/MONITORING AGENCY NAME(S) AND ADDRESS(ES)
8. PERFORMING ORGANIZATION REPORT NUMBER

NATICK/TR-03/028

12. DISTRIBUTION/AVAILABILITY STATEMIENT

Approved for public release: distribution is unlimited.

\section{SUPPLEMENTARY NOTES}

*GEO-CENTERS, INC., 190 N. Main St., Natick, MA 01760

\section{ABSTRACT}

The U.S. Army Soldier and Biological Chemical Command (SBCCOM) and the U.S. Marine Corps Systems Command (MARCORSYSCOM) conducted an Internet-based survey to receive feedback on what features and capabilities Marines would like from load bearing equipment. This was done by creating an interactive on-line survey that Marines could access from personal computers. The survey was available on the Internet from July 12002 through Aug 312002 (62 days). Information and a hyperlink to the survey were posted on the Marine Corps home page. The survey was completed by 7,037 Marines. Approximately one third $(n=2439)$ of these participants were infantry personnel. For the purposes of this report, only the responses from the Marine infantry will be cited.

\section{SUBJECT TERMIS}

MARINE CORPS PERSONNEL LOAD BEARING EQUIPMENT

INFANTRY PERSONNEL LOAD CARRYING EQUIPMENT

MOLLE(MODULAR LIGHTWEIGHT LOAD-CARRYING EQUIPMENT)

ALICE(ALL,PURPOSE LIGHTW

16. SECURITY CLASSIFICATION OF:

$$
\begin{array}{|l|l|l|}
\hline \text { a. REPORT } & \text { b. ABSTRACT } & \text { c. THIS PAGE }
\end{array}
$$

$\mathrm{U}$

U

$\mathrm{U}$

\begin{abstract}
17. LIMITATION OF ABSTRACT
\end{abstract}

SAR
LOAD CARRIAGE SYSTEM

WEIGHT ANALYSIS

FRAME RACK

RUCKSACK

VESTS

SURVEYS

INTERNET

NT) PACK ERAME

\section{NUMBER(S)}



TABLE OF CONTENTS

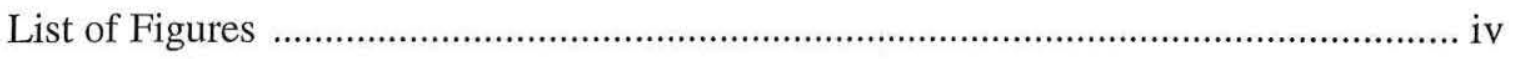

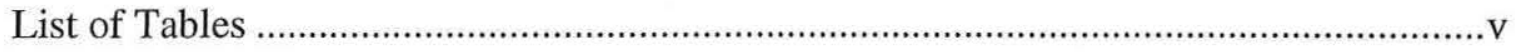

Preface and Acknowledgments............................................................................. .vi

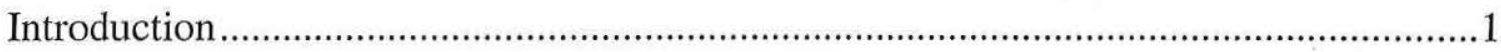

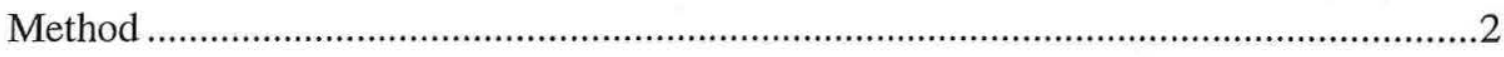

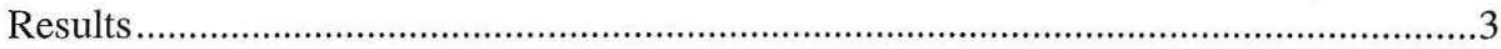

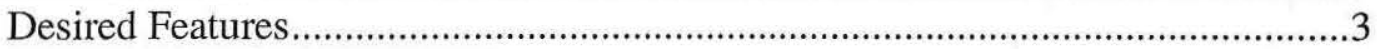

Problems with Existing Equipment ......................................................................

Problems Based on Pack ................................................................................12

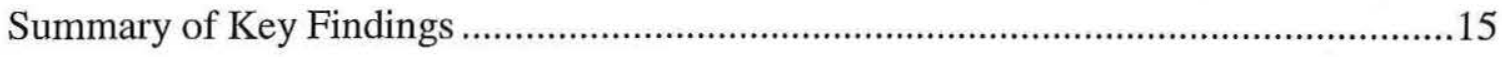

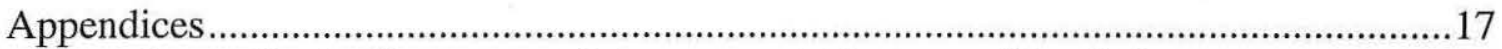

Appendix A. Summary of Responses: Infantry vs. Non-infantry .....................18

Appendix B. Screen Shots of Web Site ..............................................................

Appendix C. Script for Focus Groups..............................................................63 


\section{LIST OF FIGURES}

Figure 1. Current Pack Used by Marine Infantry ……...........................................

Figure 2. How Should a Tube Hydrations System Be Carried?................................

Figure 3. Modularity.................................................................................

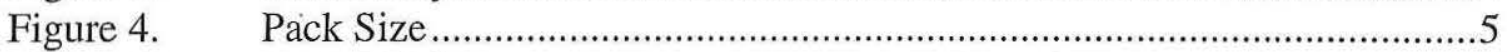

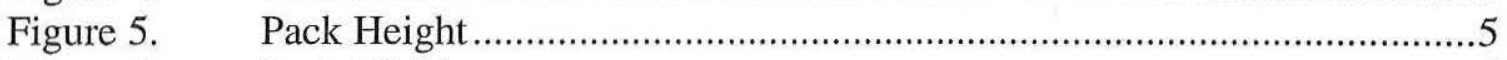

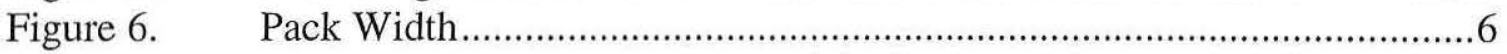

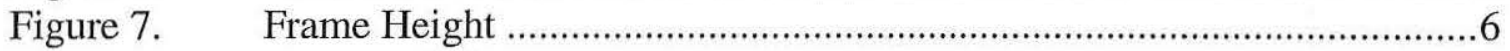

Figure 8. Frame Width ...............................................................................

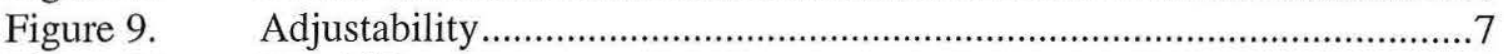

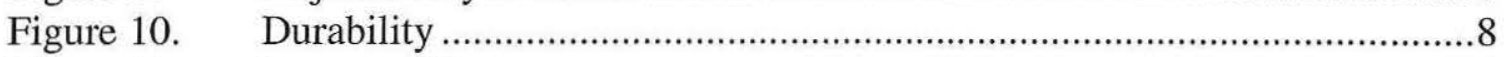

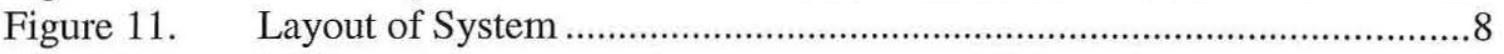

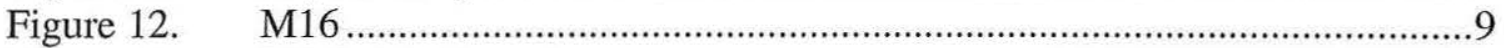

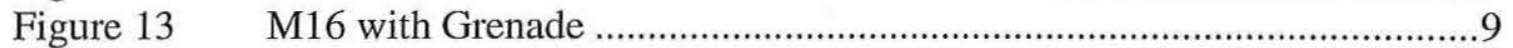

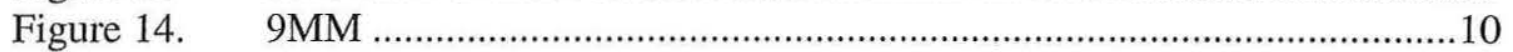

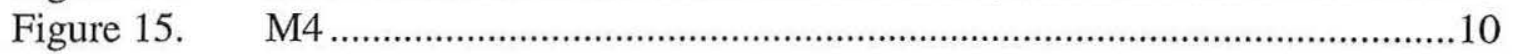

Figure 16. M4 with Grenade ..........................................................................11

Figure 17. M249 SAW ………………………...........................................11 


\section{LIST OF TABLES}

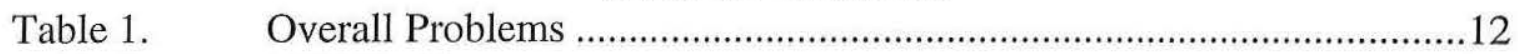

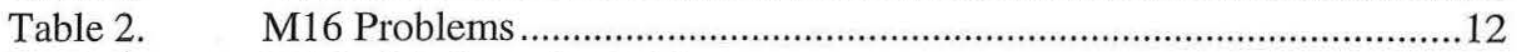

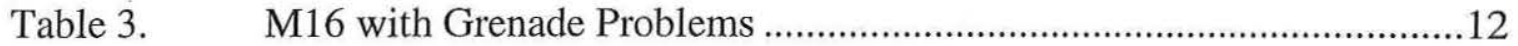

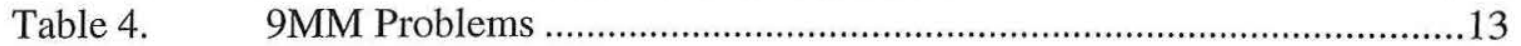

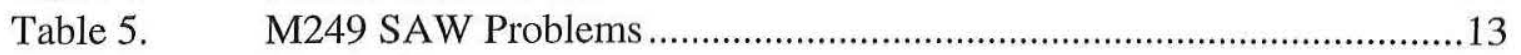

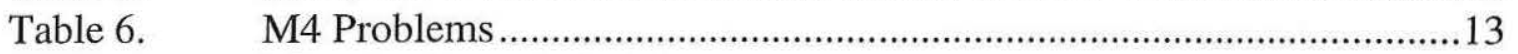

Table 7. M4 with Grenade Problems .................................................................14 


\section{PREFACE AND ACKNOWLEDGMENTS}

The U.S. Army Soldier and Biological Chemical Command (SBCCOM) and the U.S. Marine Corps Systems Command (MARCORSYSCOM) conducted an Internet-based survey to determine what features and capabilities Marines would like from load bearing equipment. This was done by creating an interactive on-line survey that Marines could access from personal computers. The survey was conducted by the Natick Soldier Center under Natick Project Number 654713 during the period April 2002 through September 2002. The survey was available on the Internet from July 12002 through Aug 312002 (62 days). Information and a hyperlink to the survey were posted on the Marine Corps home page. The survey website address was http://www.thewarriorsvoice.com

The authors would like to acknowledge the following individuals for their technical expertise, valued contributions and support to this project:

Operational Forces Interface Group

Chuck Greene

Product Optimization and Evaluation Team

Matt Kramer

Rick Bell

Simulation Technologies Inc., Natick, MA (STI)

John-Paul Briggs

Ronald D'Abbraccio

Andrew Cronk

Vannerin Ly

Mark Wishneusky

GEO-Centers Natick, MA

Steve Smith

Marine Corps

Lieutenant Colonel Gabe Patricio

Captain Dave Pinion

Marine Corps Team

John Kirk

James Mackiewicz

We especially would like to thank all of the Marines who took the time to give us their valued feedback and support. 


\section{CURRENT AND FUTURE LOAD BEARING EQUIPMENT OF THE UNITED STATES MARINES: AN ONLINE SURVEY}

\section{INTRODUCTION}

The survey was completed by 7,037 Marines. Approximately one third $(n=2439)$ of these participants were infantry Marines. Per the request of the Marine Corps, results were reported only for the infantry Marines. However, a summary of participants' responses to the survey questions based on whether they were infantry or non-infantry Marines is available in Appendix A. The majority of these Marines were on active duty $(81 \%)$. The participants varied in rank. Thirty-eight percent ranged from an E1 through E4. Forty-one percent were non-commissioned officers. The remaining participants were either officers $(21 \%)$ or warrant officers $(0.45 \%)$. The participants were evenly distributed with Marines representing all three Marine Expeditionary Forces (MEF) as well as other duty stations.

The most common weapons used by the infantry were the M16A2 (54\%) and the $9 \mathrm{~mm}(41 \%)$. As shown in figure below, the majority of the infantry listed the Modular Lightweight Load Carrying Equipment ( MOLLE) II as their currently issued load bearing system (60\%). The remaining infantry participants were using the large All Purpose Lightweight Individual Carrying Equipment (ALICE) (22\%), the medium ALICE $(9 \%)$ or the MOLLE I $(6 \%)$. Only $3 \%$ of the infantry responded that they use the lowe vector pack. The Marines indicated they were familiar with their load bearing equipment, having had an average of 3.2 years of experience with the system.

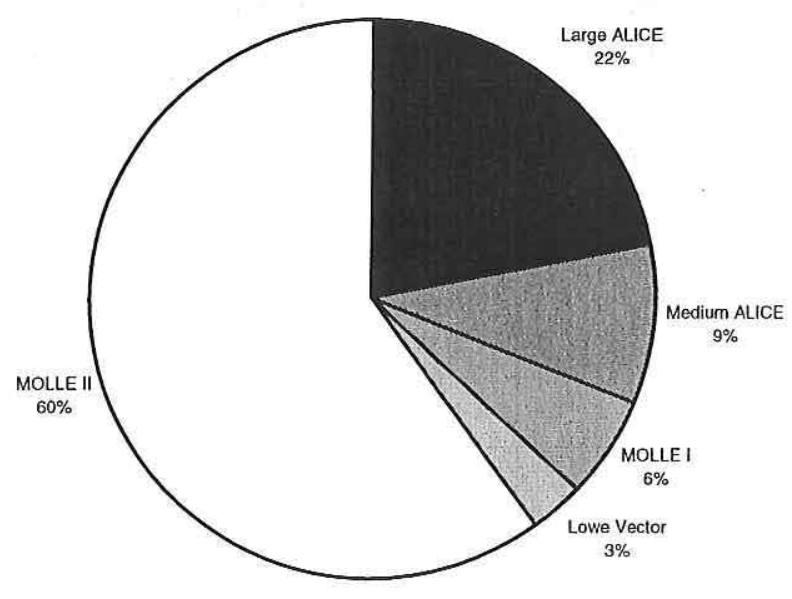

FIGURE 1. CURRENT PACK USED BY MARINE INFANTRY 


\section{METHOD}

Several focus groups were initially conducted in order to design a survey that covered as many issues as possible that Marines may be encountering with their current equipment. A copy of the script used by the focus group moderator is in Appendix B. Questions included topics such as what problems do they encounter when trying to access their gear or adjusting their packs as well as what type of frame they prefer. These focus groups were conducted at Camp Lejeune, North Carolina as well as Quantico, Virginia.

Feedback from the focus groups was reviewed and used to create the framework for the survey that consisted of four sections: background and demographics, main ruck, load bearing vest, and current use. The background questions were designed to form a profile of the survey population. Questions such as Military Occupational Specialty MOS, years of military service and duty station were asked in this section. In the second part of the survey questions were asked about what features the user would want in a main ruck sack. Questions addressed issues such as frame type and adjustability, volume and weight requirements, as well as types and numbers of pockets that the user desired. The third part of the survey contained questions to help determine load bearing vest preferences. Questions such as vest design (e.g. chest harness, vest rig etc.), number and type of pockets, and what would best suit their short combat missions were posed here. The final section was designed to find out more about the participants current load bearing equipment. These questions helped to establish how the Marines' experience with current load bearing equipment provided a basis for their responses regarding future equipment. Topics such as body armor and weapon compatibility were also addressed here.

The website for the survey was dynamic, meaning that participants were prompted with certain questions based on their individual responses. For example, on the demographics portion of the survey, participants were only prompted to fill in the section requesting their MOS and duty station if they responded that they were active in the military. Screen shots of the individual web pages are available in Appendix C. 


\section{RESULTS}

\section{DESIRED FEATURES:}

Frame

The participants were divided over what type of frame is best suited for a load carriage system with $59 \%$ of infantry marines selecting an external frame and $41 \%$ choosing an internal frame. Of those who recommended that the pack should have an external frame, $92 \%$ specified that they should be able to carry the pack without the frame attached as well as it having a stand-alone frame capability (86\%). The infantry marines were also divided on whether the pack should have different size frames $(45 \%)$ or be one size fits all $(55 \%)$.

Weight Capacity

Approximately 50\% percent indicated that the pack should be able to hold between 100 and 150 pounds. Forty percent responded that the main pack should be able to hold less than 100 pounds and $10 \%$ stated the pack should hold more than 150 pounds. Participants answered that a patrol pack should hold between 20 and 50 pounds with a mean of 32 pounds.

\section{$\underline{\text { Volume }}$}

Approximately $50 \%$ of the infantry indicated that a main ruck sack should hold between 3,500 and 5,500 cubic inches. However, $22 \%$ responded it should hold 5,500 cubic inches or more and the remaining $18 \%$ indicated that a main ruck hold less than 3,500 cubic inches.

\section{Tube Hydration System}

The overwhelming majority of infantry $(88 \%)$ indicated that they would like a load carriage system to have a tube hydration system and of those people, eighty-eight percent specified that it should be NBC capable. Marines were also asked how a tube hydration system should be carried, by checking all acceptable options. Figure 2 shows the percentage of respondents who selected each option.

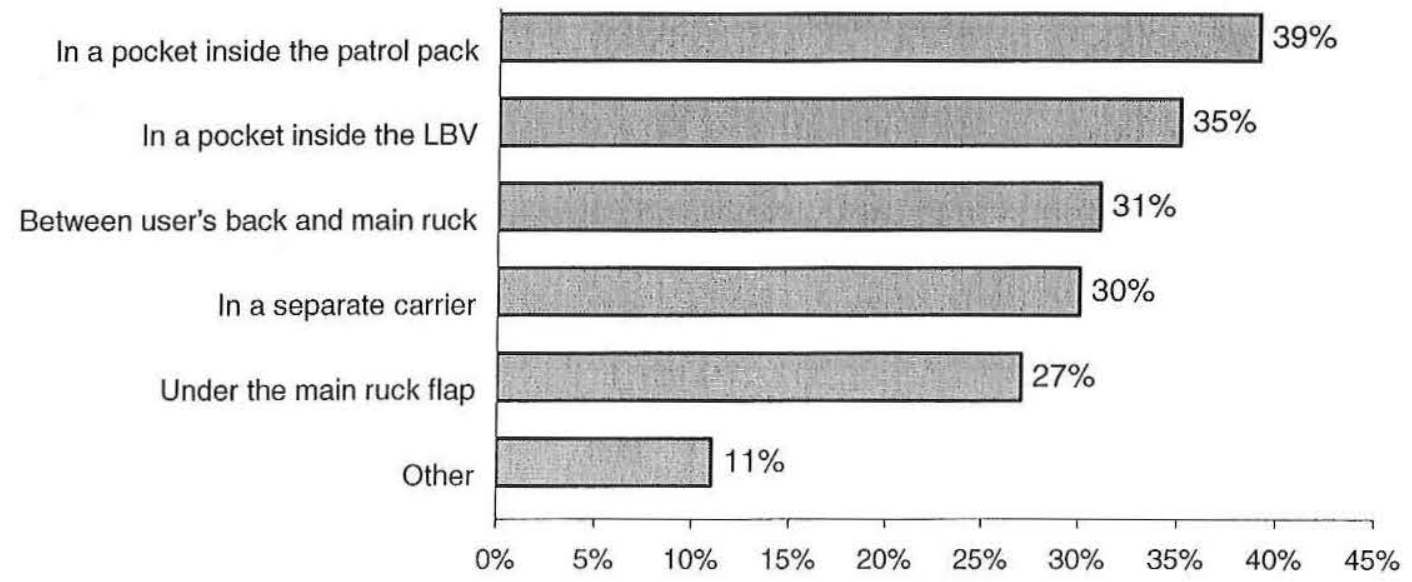

FIGURE 2. HOW SHOULD A TUBE HYDRATION SYSTEM BE CARRIED? 


\section{Pockets}

The overwhelming majority of infantry Marines indicated that a main ruck sack should contain one or more sustainment (94\%), small utility (90\%), large utility (87\%) and claymore pockets (84\%). Preferences for how these types of pockets should be attached to the main pack varied. Respondents were equally divided over whether both sustainment and claymore pockets should be permanently attached to the main pack (50\% and $43 \%$, respectively) or removable from the main pack ( $48 \%$ and $56 \%$, respectively). For the small and large utility pockets, respondents felt similarly on the attachment issue with $65 \%$ (small utility) and $67 \%$ (large utility) wanting the pockets to be permanent. Just over $55 \%$ indicated that a main pack should contain at least one pocket for $60 \mathrm{~mm}$ mortars while $44 \%$ wanted one or more for $81 \mathrm{~mm}$ mortars. For both mortar sizes approximately $23 \%$ felt that these pockets should be permanent. For the most part, respondents indicated that all of these different types of pockets should have buckle closures rather than a zipper, snap or Velcro®.

\section{Sleep System}

The majority of Marines indicated the main pack should have a sleep system (78\%) with 59\% indicating that it should be removable from the main pack and have a buckle closure. Seventy-six percent felt that it should be located at the bottom of the main pack.

\section{PROBLEMS WITH EXISTING EQUIPMENT:}

Pack ruck sack and frame

Figures 3-17 illustrate problems respondents had with their current load bearing system. The first two sections (lightest) of each bar represent people who either do not have an issue with their current pack at all or have concerns other than with the particular area being addressed in the chart. The last two sections (darkest) of each bar represent the people who do have concerns with the issue being addressed in the graph.

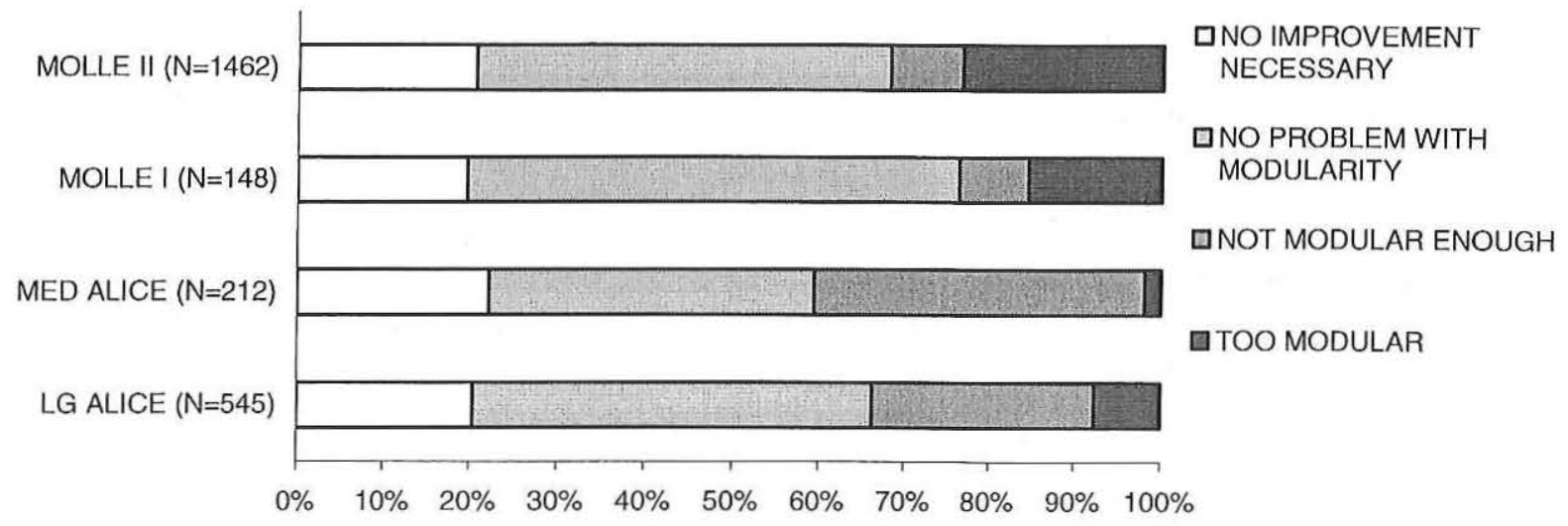

FIGURE 3. MODULARITY 
The two ALICE packs were the most problematic in terms of modularity. Both the large and medium ALICE users were concerned that their packs were not modular enough (39\% and $26 \%$, respectively). Though less concerned with modularity, MOLLE users had greater issue with too much modularity (MOLLE II 23\%, MOLLE I 16\%).

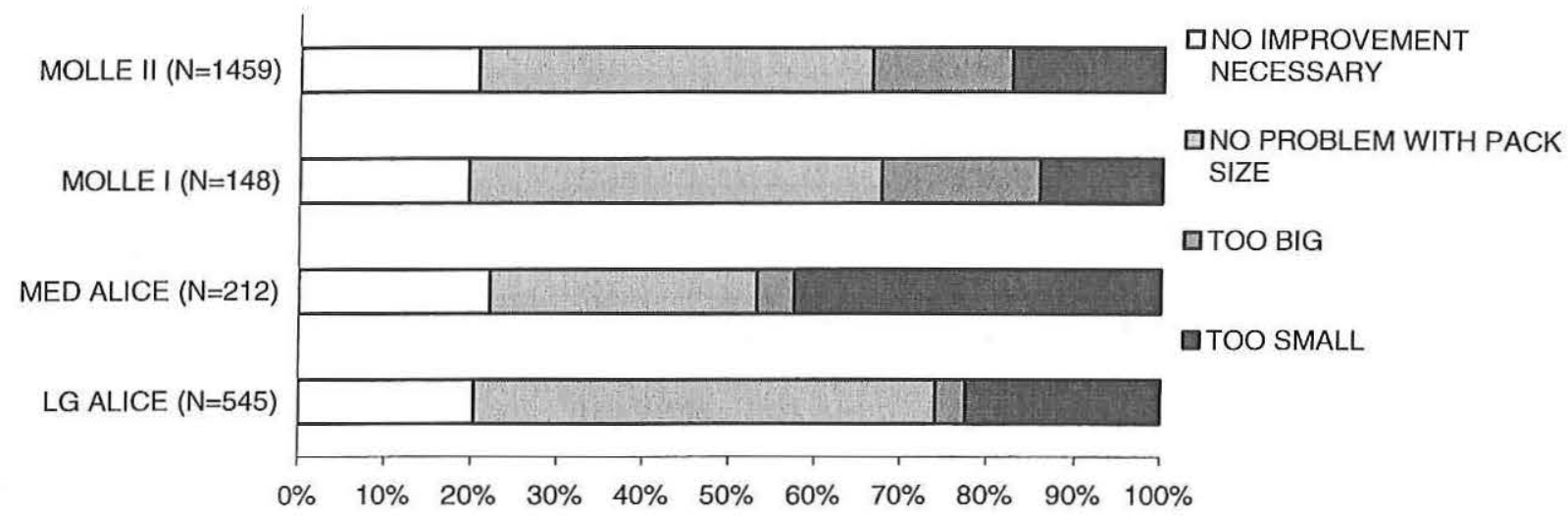

FIGURE 4. PACK SIZE

The medium ALICE users were most concerned with their pack size with $43 \%$ indicating that the pack is not large enough. Of those MOLLE users who had a problem with the size of the pack (MOLLE II 34\%, MOLLE I 32\%), half of them thought it was too big and half thought that it was too small. The large ALICE had the smallest percentage of users experiencing a problem with their with pack size (26\%).

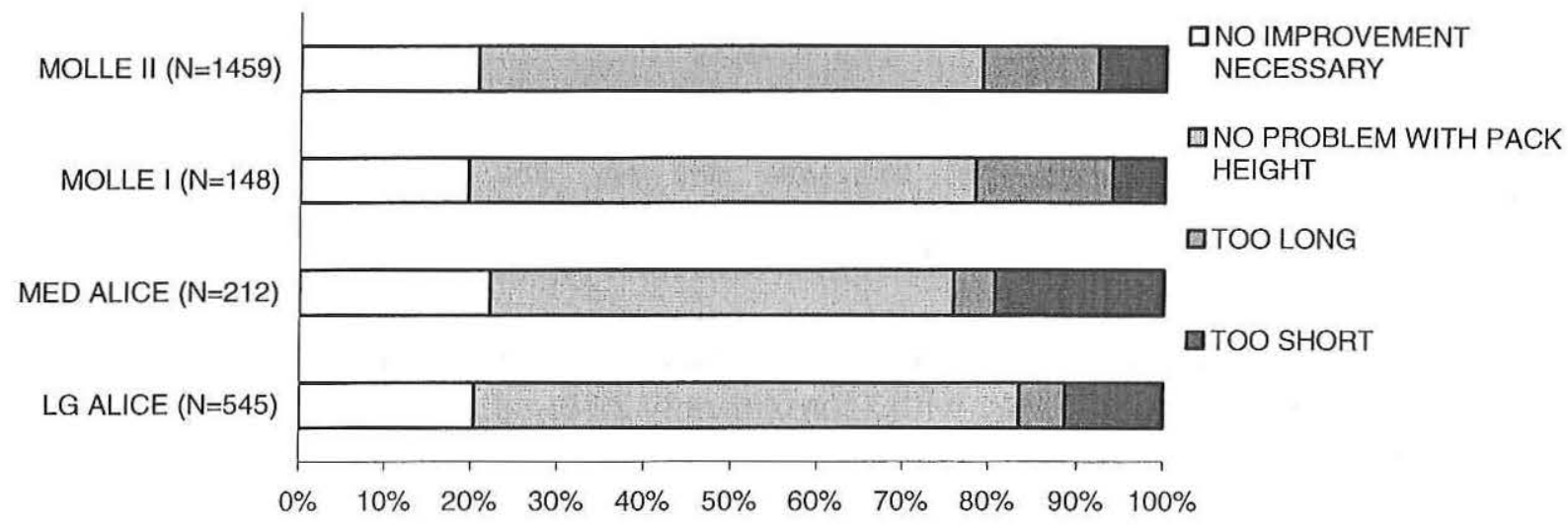

FIGURE 5. PACK HEIGHT 
In general, few respondents had an issue with their pack's height. The medium ALICE was the most problematic, with approximately $19 \%$ indicating that their pack height was too short.

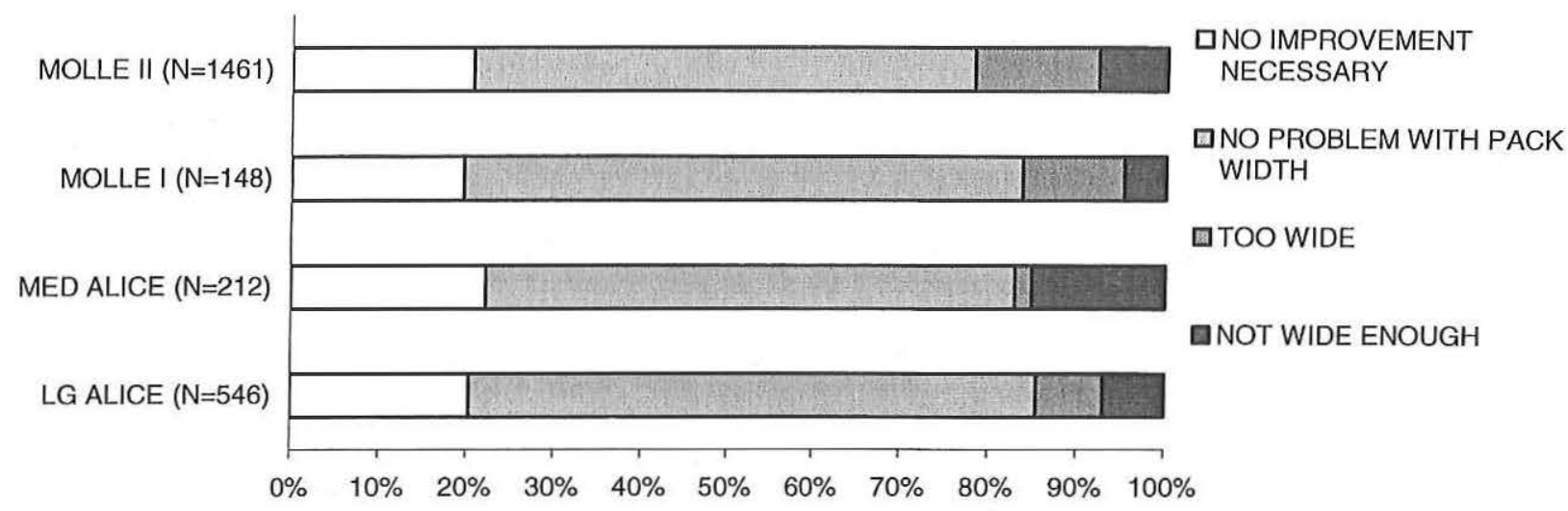

FIGURE 6. PACK WIDTH

In general, pack width was also not a problem for most respondents. The greatest problem areas noted were that the MOLLE II was too wide (14\% of users) and the medium ALICE was not wide enough (15\%).

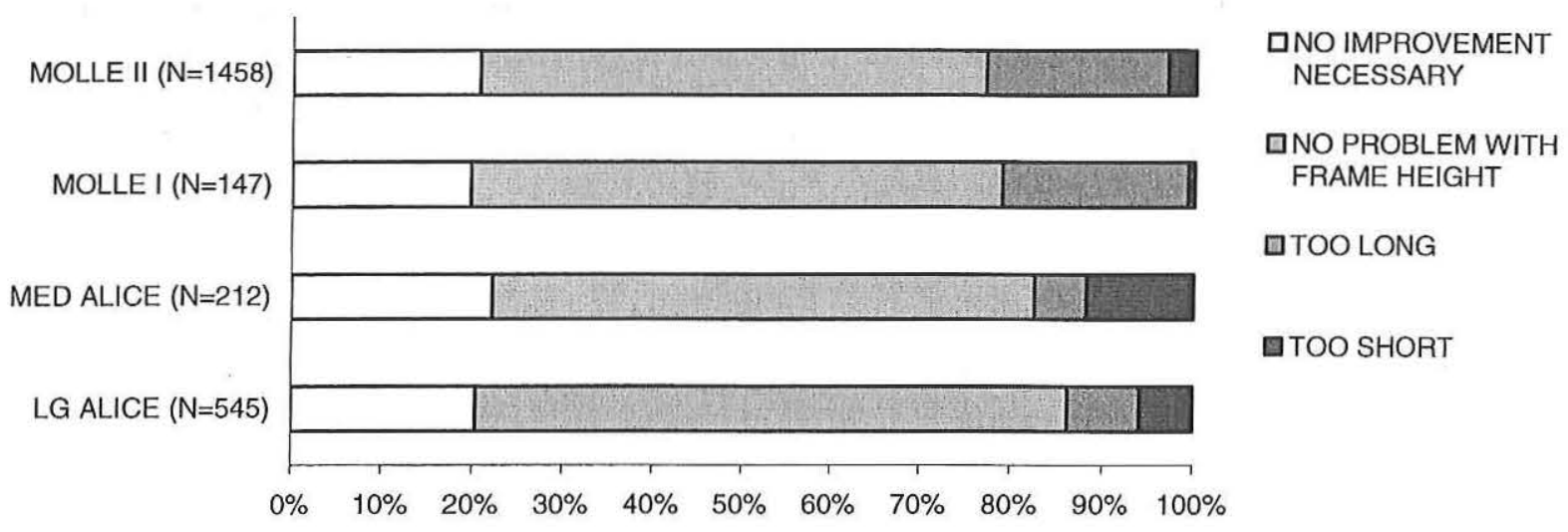

FIGURE 7. FRAME HEIGHT

Frame height was also not a problematic area. MOLLE users were the most dissatisfied with their packs, with approximately $20 \%$ stating that their pack frame was too long. 


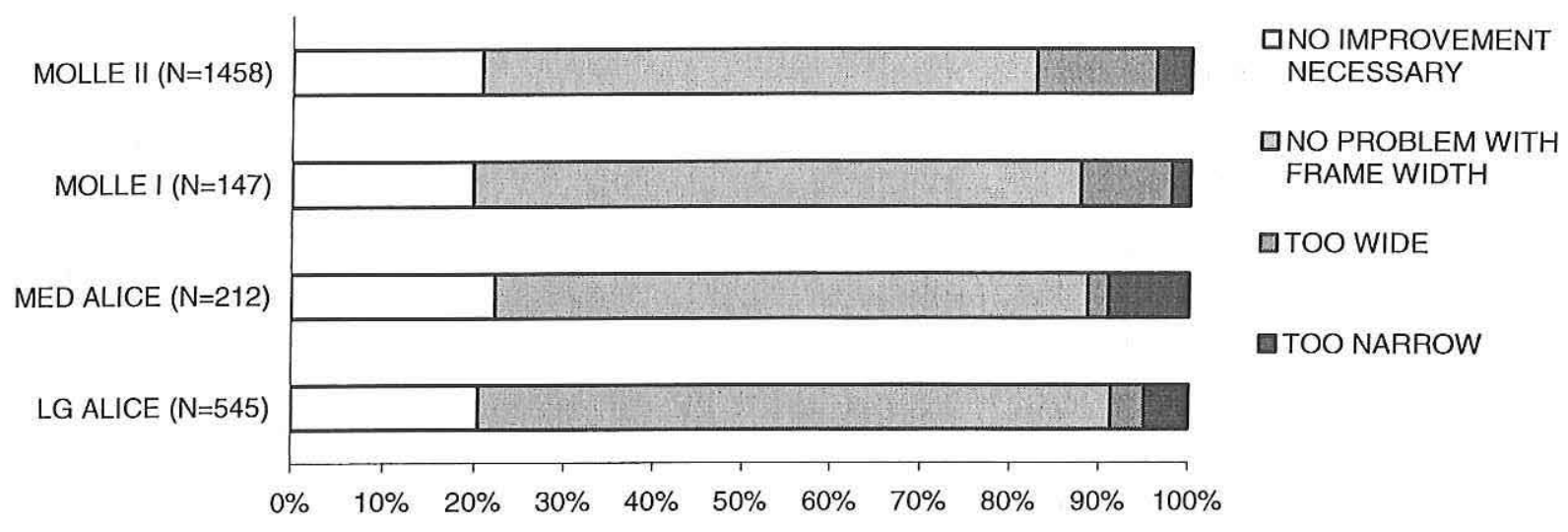

FIGURE 8. FRAME WIDTH

The MOLLE II users showed the most concern over their frame width with $13 \%$ responding that their frame was too wide. The MOLLE I users were second in frame width dissatisfaction with approximately $10 \%$ also indicating that their frame was too wide. Only a small percentage of both the large and medium ALICE users indicated any frame width concerns.

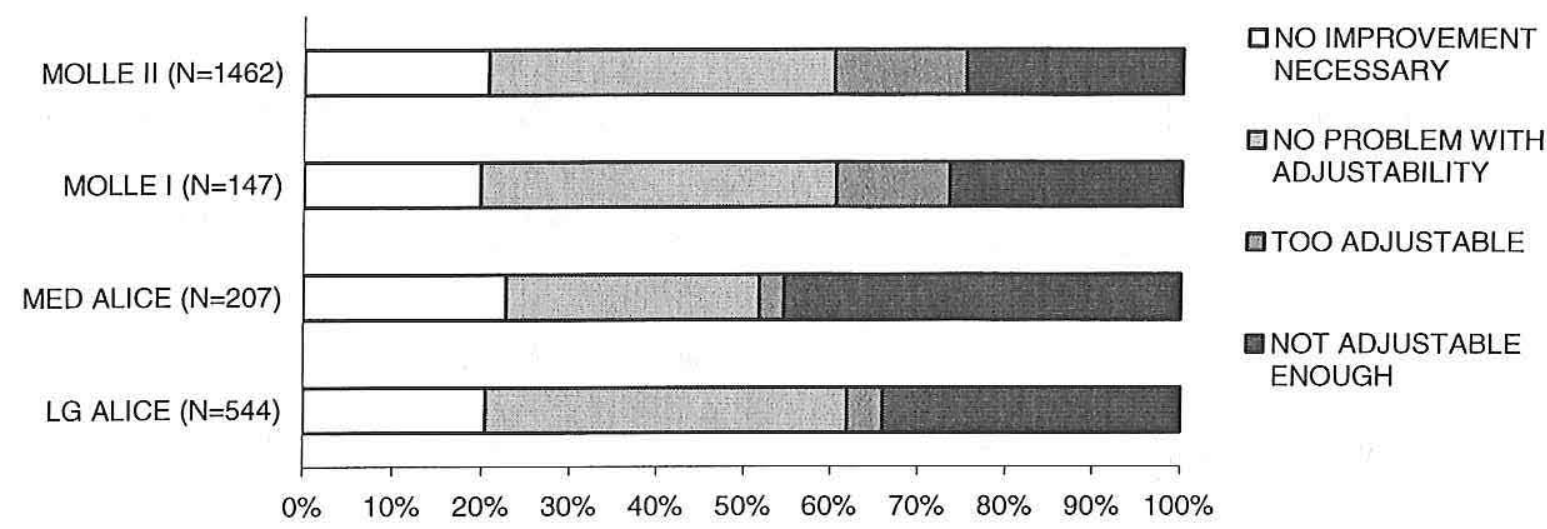

FIGURE 9. ADJUSTABILITY

Pack adjustability was an area of concern for more of the respondents. The medium ALICE users indicated the greatest level of concern, with $45 \%$ stating that the pack was not adjustable enough. Among the large ALICE users, 34\% stated that the pack was not adjustable enough. Both of the MOLLE groups reported similar levels of concern with approximately $25 \%$ indicating that their packs were not adjustable enough. 


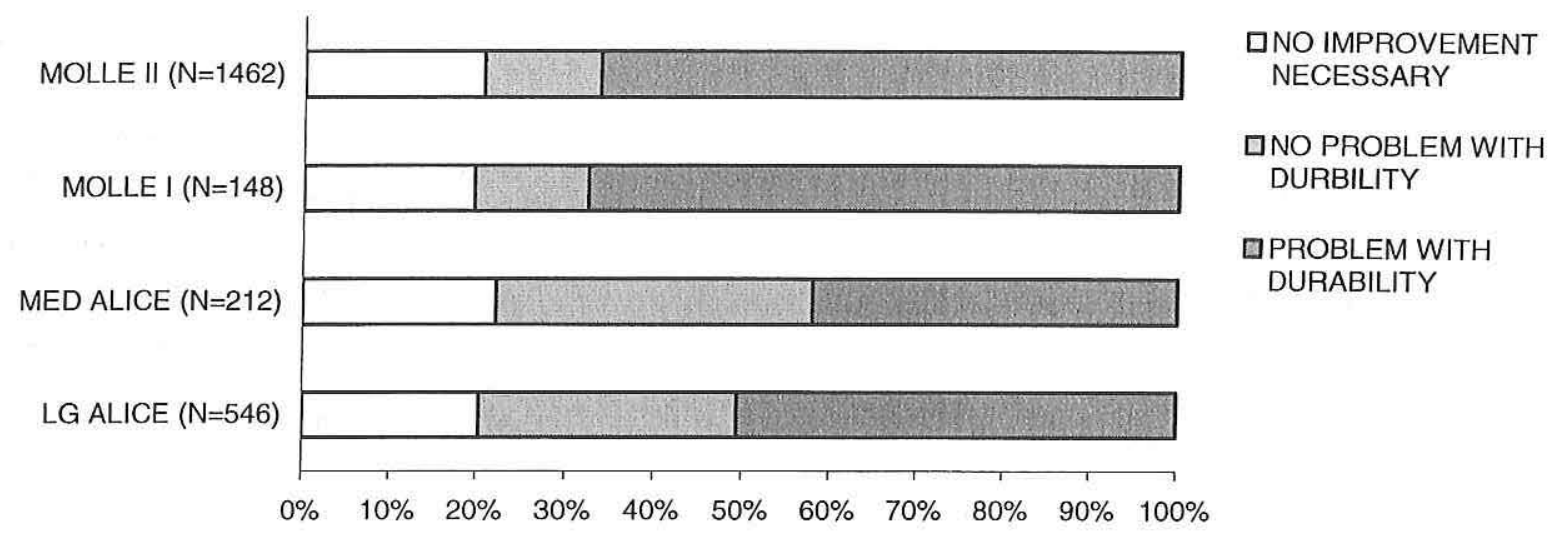

FIGURE 10. DURABILITY

Durability was also a more significant problem area for all pack groups. Approximately $67 \%$ of both the MOLLE I and II users indicated that they had a problem with durability. Both of the ALICE groups also showed a high level of concern with $50 \%$ of large ALICE users and $42 \%$ of medium ALICE users responding that their pack has a durability problem.

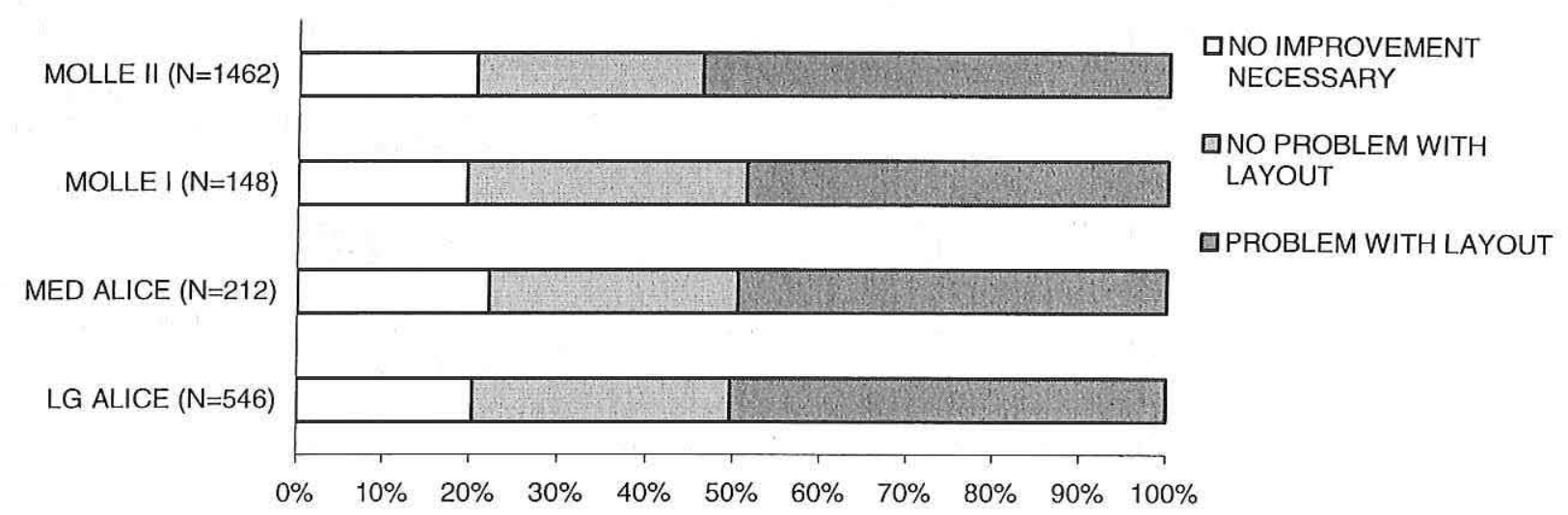

FIGURE 11. LAYOUT OF SYSTEM

System layout also proved to be a strong area of concern for all pack categories. Fifty-three percent of MOLLE II users indicated that they had a problem with the layout of their systems. All of the three remaining categories of users responded similarly, with approximately $50 \%$ showing that they had a concern with their system's layout. 
Problems with weapon interference

The graphs below illustrate the different problems respondents were experiencing between their load bearing equipment and their weapons. The white portion of the bars indicates the respondents were not experiencing any problems between their weapon and equipment. The lighter gray color indicates that they are having a problem with this particular weapon, but not for the given category. The darkest gray area represents those individuals who are having a problem with their weapon and in the specific category.

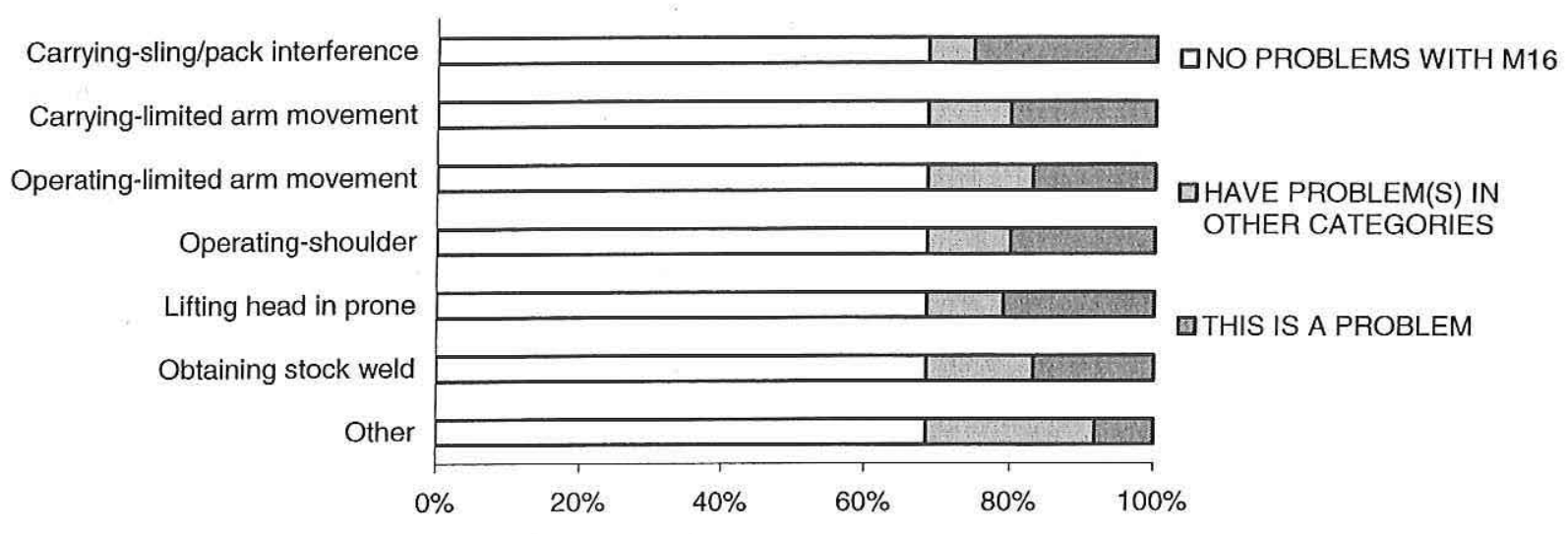

FIGURE 12. M16 (N=1314)

Overall, $64 \%$ of respondents reported no problems with weapon/pack interference. This graph shows a similar trend between level of concern and problem categories. Approximately $20 \%$ of subjects had a problem in each problem category. However, respondents indicated a slightly greater concern (25\%) over interference between the sling and pack when carrying the M16.

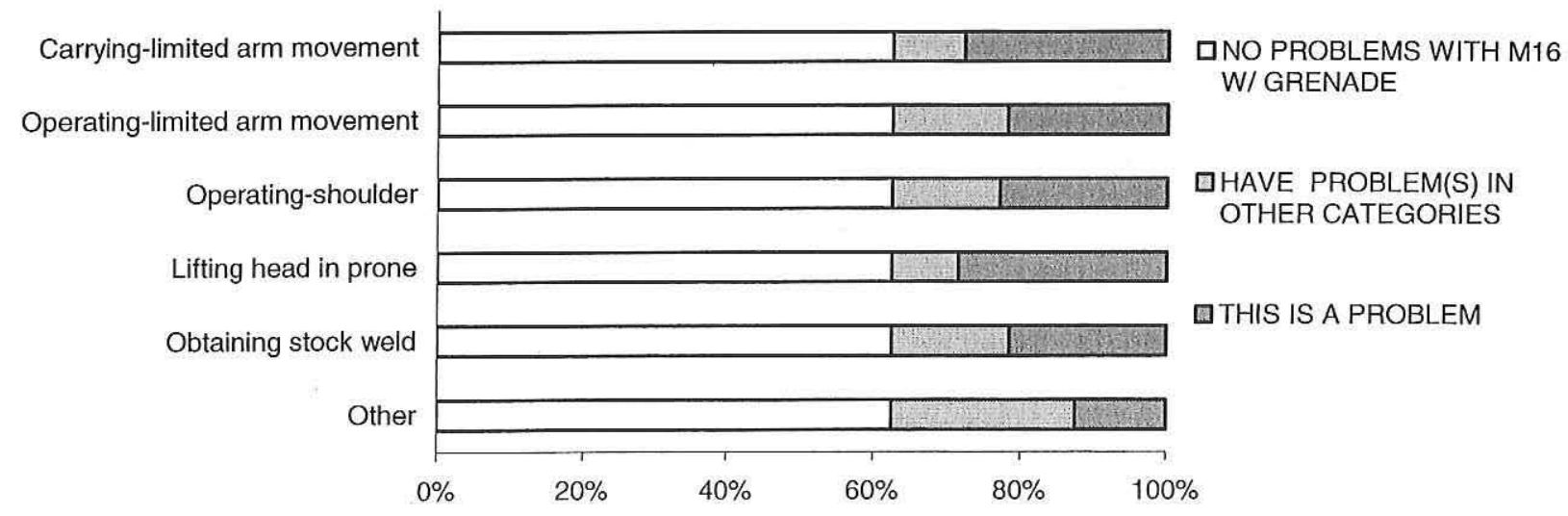

FIGURE 13. M16 WITH GRENADE ( $=288)$

This graph illustrates that over $60 \%$ of respondents did not have a problem with their load carrying equipment and their M16 with M203 grenade launchers. Of those 
who did respond that they had a problem, $28 \%$ of them found it to be with their arm movement being limited while carrying the weapon and with not being able to lift their heads when in the prone position.

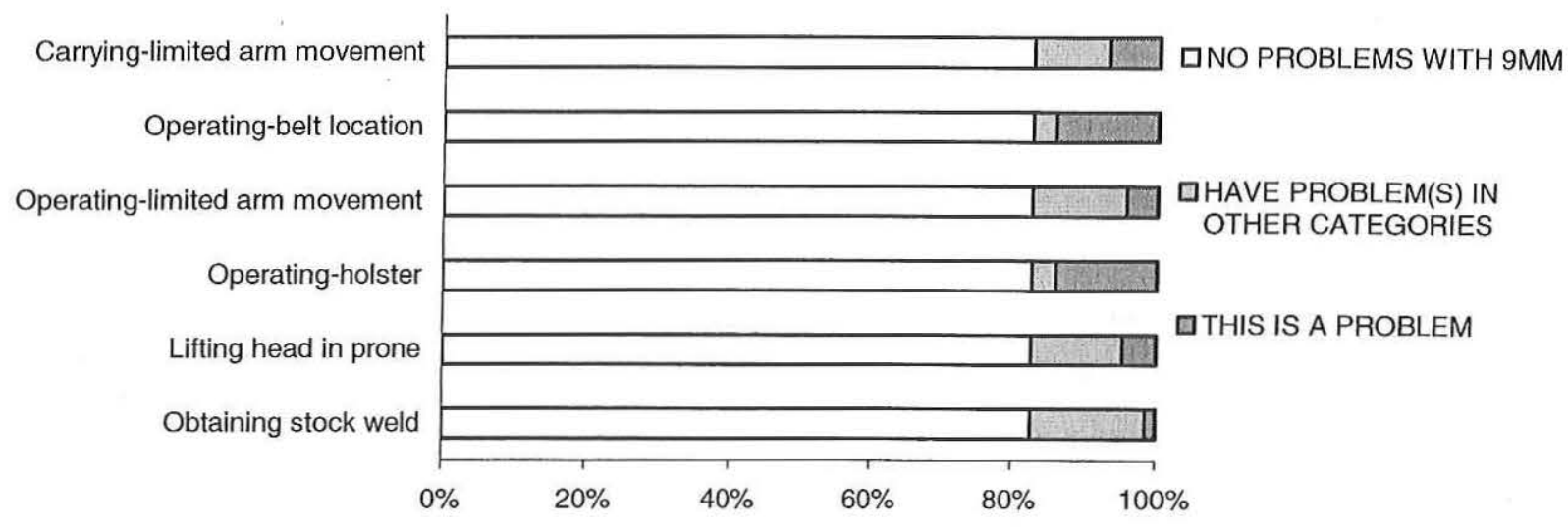

FIGURE 14. 9MM $(\mathrm{N}=996)$

Over $80 \%$ of the infantry Marines answered that they did not have a problem with their current load carrying equipment and the $9 \mathrm{~mm}$ pistol. Of those who did indicate having a problem, their biggest concerns were finding a good location on their belt for the weapon (14\%) and drawing the weapon from the holster (14\%).

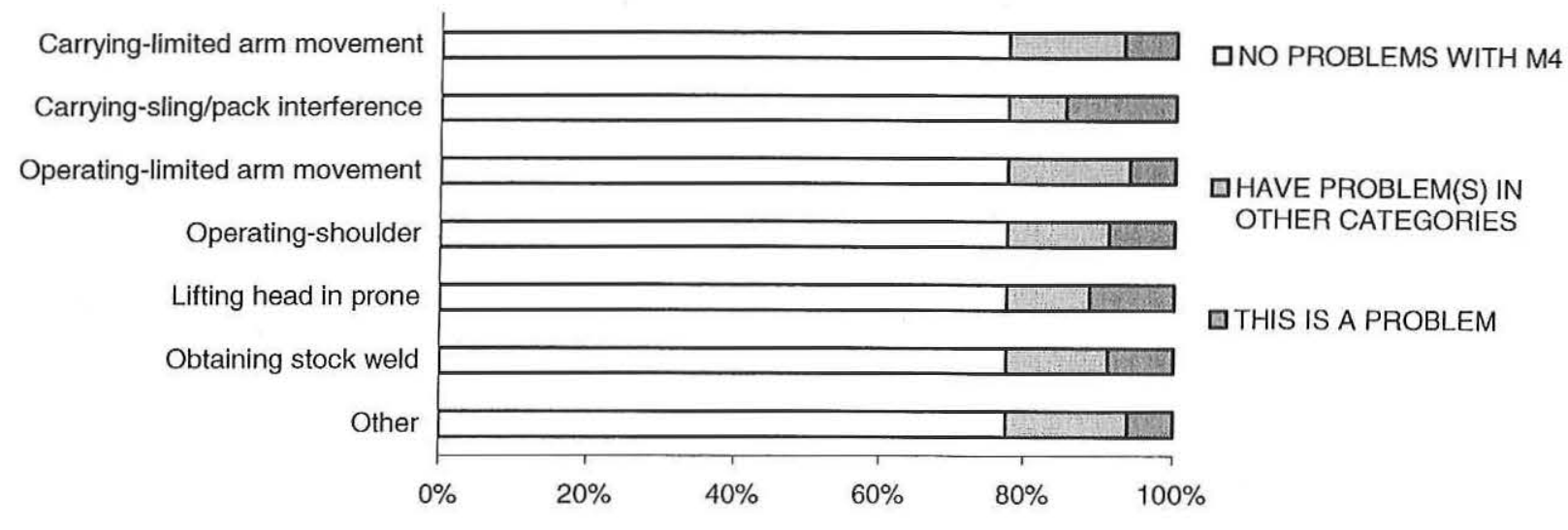

FIGURE 15. M4 (N=116)

In general, respondents did not have a lot of concern over load bearing equipment interference when using the M4 rifle. Almost 80\% indicated that they did not have any problems at all. However, $15 \%$ of the Marines answered that they had problems due to interference between the sling and pack when carrying the M4. 


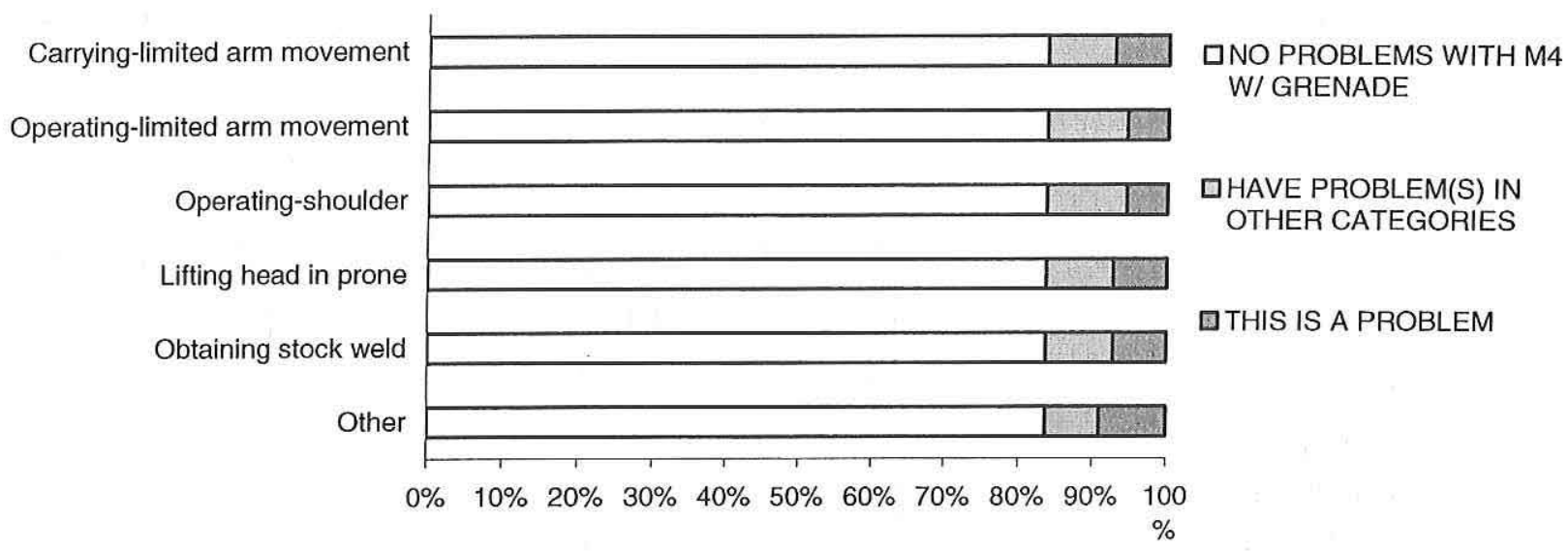

\section{FIGURE 16. M4 WITH GRENADE (N=55)}

The M4 with M203 grenade launcher did not prove to be very problematic for the respondents when they were wearing their load bearing equipment. Over $80 \%$ of the Marines indicated that they did not experience any problems at all.

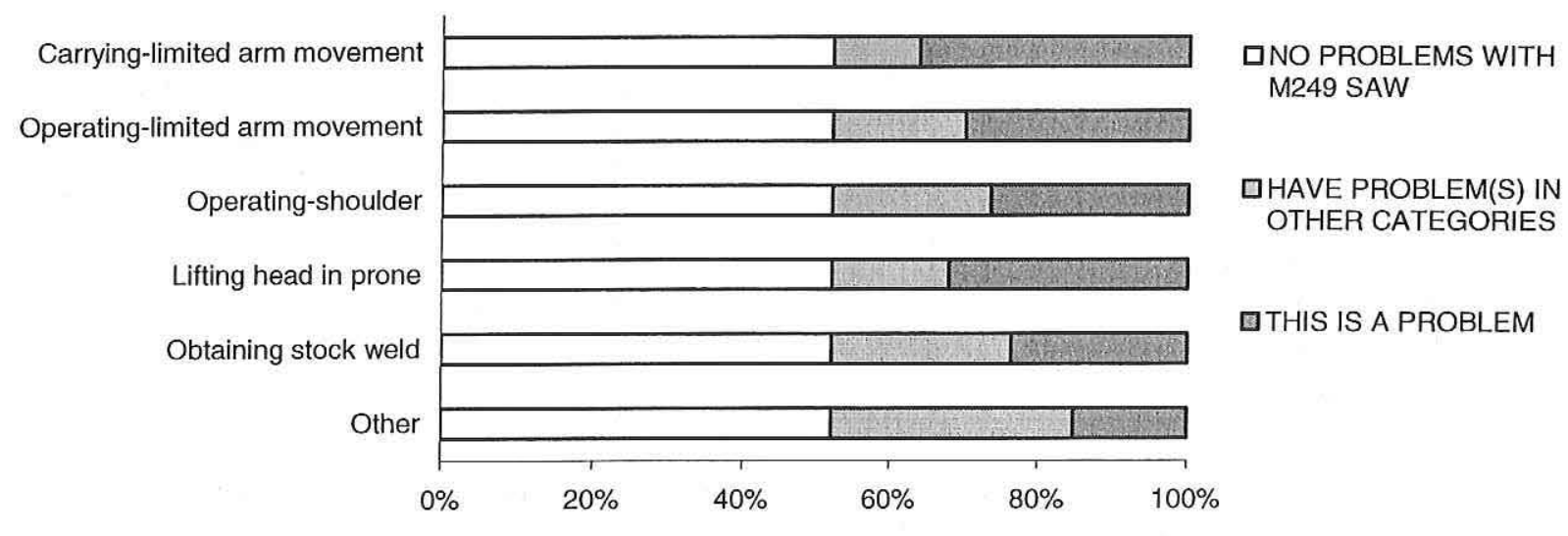

FIGURE 17. M249 SAW (N=144)

Just over $50 \%$ of the infantry Marines that carry the M249 SAW (squad automatic weapon) responded that they had a problem between their load bearing equipment and their weapon. Thirty-six percent of respondents indicated that carrying the weapon limited arm movement while 30\% answered that operating the weapon limited arm movement as well. Respondents also indicated that they experienced problems when trying to lift their head when in the prone position (32\%). 


\section{PROBLEMS BASED ON PACK:}

Table one shows the breakdown, based on pack, of Marines who indicated that they had problems with the weapons listed in the survey. In general, a group has to have a minimum of 50 Marines in order to make a statistically significant comparison.

\begin{tabular}{|l|c|c|c|}
\cline { 2 - 4 } \multicolumn{1}{c|}{} & \multicolumn{3}{c|}{ TABLE 1. OVERALL PROBLEMS } \\
\cline { 2 - 4 } & $\begin{array}{c}\text { PROBLEMS WITH } \\
\text { WEAPON }\end{array}$ & TOTAL & $\%$ WITH PROBS \\
\hline TOTAL & 796 & 2913 & 27 \\
\hline LARGE ALICE & 102 & 703 & 15 \\
\hline MEDIUM ALICE & 47 & 258 & 18 \\
\hline MOLLE I & 42 & 164 & 26 \\
\hline MOLLE II & 579 & 1701 & 34 \\
\hline
\end{tabular}

Across all weapon systems, both of the MOLLE (34\% and 26\%) users had more problems than either of the ALICE groups (15\% and 18\%).

Tables 2-7 represent the Marines who indicated that they had a problem with pack weapon compatibility for the specific weapon listed.

\begin{tabular}{|l|c|c|c|}
\cline { 2 - 4 } \multicolumn{1}{c|}{} & \multicolumn{3}{c|}{ TABLE 2. M16 PROBLEMS } \\
\cline { 2 - 4 } \multicolumn{1}{c|}{} & $\begin{array}{c}\text { PROBLEMS WITH } \\
\text { M16 }\end{array}$ & TOTAL & \% WITH PROBS \\
\hline TOTAL & 413 & 1314 & 31 \\
\hline LARGE ALICE & 34 & 255 & 13 \\
\hline MEDIUM ALICE & 25 & 112 & 22 \\
\hline MOLLE I & 27 & 75 & 36 \\
\hline MOLLE II & 312 & 835 & 37 \\
\hline
\end{tabular}

In general, both of the MOLLE users had more problems with pack weapon compatibility than either of the ALICE groups.

\section{TABLE 3. M16 WITH GRENADE PROBLEMS}

\begin{tabular}{|l|c|c|c|}
\cline { 2 - 4 } & $\begin{array}{l}\text { PROBLEMS WITH } \\
\text { M16 W/GRENADE }\end{array}$ & TOTAL & \% WITH PROBS \\
\hline TOTAL & 108 & 288 & 38 \\
\hline LARGE ALICE & 15 & 72 & 21 \\
\hline MEDIUM ALICE & 5 & 19 & 26 \\
\hline MOLLE I & 3 & 16 & 19 \\
\hline MOLLE II & 82 & 171 & 48 \\
\hline
\end{tabular}


The only notable difference for M16 with grenade users was between the MOLLE II and the large ALICE groups. Nearly half of the MOLLE II group had at least one problem with weapon pack compatibility. There are not enough subjects in the other pack categories to make a comparison.

\begin{tabular}{|l|c|c|c|}
\cline { 2 - 4 } \multicolumn{1}{c|}{} & \multicolumn{3}{c|}{ TABLE 4. 9MM PROBLEMS } \\
\cline { 2 - 4 } & $\begin{array}{c}\text { PROBLEMS WITH } \\
9 \mathrm{MM}\end{array}$ & TOTAL & \% WITH PROBS \\
\hline TOTAL & 171 & 996 & 17 \\
\hline LARGE ALICE & 25 & 226 & 11 \\
\hline MEDIUM ALICE & 9 & 106 & 12 \\
\hline MOLLE I & 7 & 58 & 21 \\
\hline MOLLE II & 123 & 578 & \\
\hline
\end{tabular}

In general, none of the pack groups had a significant number of problems when carrying the $9 \mathrm{~mm}$.

\begin{tabular}{|l|c|c|c|}
\cline { 2 - 4 } \multicolumn{1}{c|}{} & \multicolumn{2}{c|}{ TABLE 5. M249 SAW PROBLEMS } \\
\cline { 2 - 4 } & $\begin{array}{c}\text { PROBLEMS WITH } \\
\text { M249 SAW }\end{array}$ & TOTAL & \% WITH PROBS \\
\hline TOTAL & 69 & 144 & 48 \\
\hline LARGE ALICE & 10 & 30 & 33 \\
\hline MEDIUM ALICE & 5 & 13 & 38 \\
\hline MOLLE I & 4 & 12 & 33 \\
\hline MOLLE II & 50 & 87 & 57 \\
\hline
\end{tabular}

Although the sample size is on the smaller side, it should be noted that almost $60 \%$ of MOLLE II users reported that they had at least one problem with pack compatibility when carrying or using the M249 SAW.

In the following charts, there are not enough respondents in most of the categories to draw any significant conclusions.

\begin{tabular}{|l|c|c|c|}
\cline { 2 - 4 } \multicolumn{1}{c|}{} & \multicolumn{3}{c|}{ TABLE 6. M4 PROBLEMS } \\
\cline { 2 - 4 } & $\begin{array}{c}\text { PROBLEMS WITH } \\
\text { M4 }\end{array}$ & TOTAL & $\%$ WITH PROBS \\
\hline TOTAL & 26 & 116 & 22 \\
\hline LARGE ALICE & 14 & 84 & 17 \\
\hline MEDIUM ALICE & 3 & 8 & 38 \\
\hline MOLLE I & 0 & 1 & 0 \\
\hline MOLLE II & 8 & 18 & 44 \\
\hline
\end{tabular}




\begin{tabular}{|l|r|r|r|}
\cline { 2 - 4 } & \multicolumn{3}{c|}{ TABLE 7. M4 W/TH GRENADE PROBLEMS } \\
\cline { 2 - 5 } & $\begin{array}{l}\text { PROBLEMS WITH } \\
\text { M4 W/ GRENADE }\end{array}$ & TOTAL & $\%$ WITH PROBS \\
\hline TOTAL & 9 & 55 & 16 \\
\hline LARGE ALICE & 4 & 36 & N/A \\
\hline MEDIUM ALICE & 0 & 0 & 50 \\
\hline MOLLE I & 1 & 2 & 33 \\
\hline MOLLE II & 4 & 12 & 11 \\
\hline
\end{tabular}




\section{SUMMARY OF KEY FINDINGS}

- $59 \%$ of infantry respondents indicated that a main pack should have an external frame.

- Approximately 50\% of Marines answered that a main pack should hold between 100 and 150 pounds.

- Respondent's mean for the patrol pack weight capacity was 32 pounds.

- The majority of Marines (89\%) think that a load carriage system should have a tube hydration system.

- The majority of Marines responded that a main pack should have one or more sustainment, small utility, large utility and claymore pockets.

- These types of pockets should have buckle closures.

- Marines indicated that they would like their load carriage equipment to have a sleep system $(78 \%)$.

- The main areas of concern for most of the different pack users were their pack's modularity, size, adjustability and durability, layout.

- Most had a compatibility problem with the M249 SAW.

- In general, both MOLLE I and MOLLE II users had more with pack weapon compatibility.

This document reports research undertaken at the U.S. Army Soldier and Biological Chemical Command,

15 Soldier Systems Center, Natick, MA, and has been assigned No. NATICK/TR-03/028 in a series of reports approved for publication. 
INTENTIONALLY LEFT BLANK 
APPENDICES 
Appendix A.

Summary of Responses: Infantry vs. Non-Infantry 


\section{Participants:}

Seven thousand and thirty-seven people completed the on-line survey of which 2,439 were infantry and 4,598 were non-infantry. The majority of these participants were active duty ( $79 \%$ infantry, $78 \%$ non-infantry) enlisted ( $81 \%$ infantry, $83 \%$ non-infantry) males in the military (99\% infantry, $95 \%$ non-infantry). The subjects were evenly distributed with participants representing all three MEF's as well as other duty stations.

\section{Key Findings: Main Ruck Sack}

\section{Current Use:}

The majority of the marine infantry are currently using the MOLLE II with a significant minority using the large ALICE pack (60\% and $22 \%$, respectively). The majority of non-infantry marines however, are currently using either the medium ALICE pack $(40 \%)$ or the MOLLE II (34\%). Both of these groups were familiar with their currently issued system with a mean number of years of experience of 3.2 years for the infantry and 4.4 years for the non-infantry.

\section{Features:}

The participants were fairly divided over what type of frame is best suited for a load carriage system with a 59\% (58\% non infantry) to $41 \%$ ( $42 \%$ non-infantry) split over an external verses an internal frame. However, of those who recommended that the pack have an external frame, $92 \%$ infantry and $93 \%$ of the non-infantry would like to be able to carry the pack without the frame attached as well as it having a stand-alone capability ( $86 \%$ infantry, $90 \%$ non-infantry). Both the infantry and the non-infantry were also divided on whether the pack should have different size frames or be one size fits all with a slight majority choosing the one size fits all option (55\%).

Feedback on the question of what the weight capacity of the main pack should be showed that approximately $40 \%$ of both the infantry and non-infantry participants would like the main pack to hold less than 100 pounds, $50 \%$ would like the pack to hold between 100 and 150 pounds, and $10 \%$ would like the pack to hold more than 150 pounds. Both groups would like the patrol pack to hold between 20 and 50 pounds with a mean of 32 pounds.

For volume capacity, approximately $18 \%$ of the infantry and $20 \%$ of the non-infantry indicated that a main ruck sack should hold less than 3,500 cubic inches, $50 \%$ of the infantry and $60 \%$ of the non-infantry responded it should hold between 3,500 and 5,500 cubic inches and $22 \%$ of the infantry and $30 \%$ of the non-infantry responded it should hold more than 5,500 cubic inches or more. Both groups would like the patrol pack to hold approximately 1400 cubic inches.

The overwhelming majority of subjects indicated that they would like a load carriage system with a tube hydrations system $(88 \%$ infantry, $89 \%$ non-infantry). Most would like the main ruck to have removable pockets except for both the small and large utility type pockets which they would like to be permanent.

\section{Key Findings: Load Bearing Vest}

\section{Current Use:}

The majority of infantry marines use the MOLLE II FLC when in the field (60\%) with a significant minority using the ALICE pistol belt and suspenders (15\%). The non-infantry were divided among the MOLLE II FLC (33\%), Tactical load bearing vest $(26 \%)$ and the ALICE pistol belt and suspenders (24\%).

\section{Load Bearing Vest Features:}

Feedback on the LBV did not indicate a clear preference on what type of equipment should be used to carry a fighting load. Twenty-nine percent of the infantry chose a modular vest rig design, $27 \%$ chose a vest rig design, and $22 \%$ chose the cartridge belt with suspenders. Of the non-infantry, only a slight majority chose the modular vest rig design with a close second being the vest rig design (26\%).

In general, subjects responded that they would like the pockets on their load bearing vest to be removable.

\section{Additional Analyses:}

Additional analyses will look at the problems and or issues surrounding participants various currently issued equipment. Specifically, responses to questions based on compatibility between current load bearing equipment and weapons carried as well as body armor and tube hydration systems. Also, the participant's preferences on the pockets for a main ruck as well as a LBV will be further examined. 
Background/Demographics:

Subjects:

Age:

Mean

Median

Gender:

Male

Female

Component:

Active

Reserve

Veteran

Civilian

\section{Rank:}

Enlisted

Officers or Warrant Officers

Missing data/NA

\section{Duty Station:}

I MEF

II MEF

III MEF

Marine Forces Reserve

Other

missing data/NA

\section{Weapon Carried:}

M16A2

M16A2 with M203 Grenade Launcher

M4

M4 with M203 Grenade Launcher

$9 \mathrm{~mm}$

M249 SAW
Infantry

2439

27.6

26

$99 \%$

less than $1 \%$

$81 \%$

$19 \%$

less than $1 \%$

none

$79 \%$

$21 \%$

none

$27 \%$

$27 \%$

$8 \%$

$20 \%$

$18 \%$

none

Infantry

$54 \%$

$12 \%$

$5 \%$

$2 \%$

$41 \%$

$6 \%$
Non-Infantry

4598

Total: 7037
$95 \%$

$5 \%$

27.4

26

$83 \%$

$12 \%$

$3 \%$

$2 \%$

$78 \%$

$17 \%$

$5 \%$

$23 \%$

$22 \%$

$11 \%$

$15 \%$

$24 \%$

$5 \%$

Non-Infantry

$54 \%$

$5 \%$

$1 \%$

$0 \%$

$49 \%$

$3 \%$

What type of frame is best suited for a load carriage system?

External

Internal
$59 \%$

$41 \%$
$58 \%$

$42 \%$ 
Out of those who selected "external"...

Should you be able to carry the pack without the frame attached?

YES

Infantry

$92 \%$
Non-Infantry

$93 \%$

Should the frame have a stand-alone capability? (e.g. you can carry MRE cases, ammunition, or 5 gallon water cans on it)

YES

Infantry

$86 \%$
Non-Infantry

$90 \%$

Should the pack have different size frames, or one size fits all (adjustable)?

Infantry

$45 \%$

$55 \%$
Non-Infantry

$45 \%$

$55 \%$

One size fits all

The pack should be capable of carrying:

Main Ruck along with any items that you would attach to the outside of the ruck (example: machine gun or mortar base plate attached to outside)

Mean

100 pounds or less
Infantry

$110 \mathrm{lbs}$.

$59 \%$
Non-Infantry

$104 \mathrm{lbs}$.

$64 \%$

Patrol Pack:

Mean

32 lbs.

$32 \mathrm{lbs}$.

Total system weight carrying capability:

Mean 142 lbs.

136 lbs.

Approximately how many cubic inches should the pack hold?

Main Ruck Sack:

Mean

4479 in $^{3}$

4500 cubic inches or less

$63 \%$

4562 in $^{3}$

$56 \%$ 
Patrol Pack:

Mean
Infantry
1404 in $^{3}$

Total system volume carrying capability:

Mean

How many access points (openings) should the pack have?

Top

Bottom

Side
5883 in $^{3}$
$99 \%$

$32 \%$

$49 \%$
$98 \%$

$28 \%$

$67 \%$
Non-Infantry

$1377 \mathrm{in}^{3}$

$5939 \mathrm{in}^{3}$ 
What type of pockets should the main pack have? (Fill in chart below)

\begin{tabular}{|c|c|c|c|c|c|c|c|c|c|c|c|}
\hline \multicolumn{3}{|c|}{ How Many } & \multicolumn{3}{|c|}{ Attachment* } & \multicolumn{3}{|c|}{ Type of closure } & \multicolumn{3}{|c|}{ Placement } \\
\hline \multirow{4}{*}{$\begin{array}{l}\text { Sustainment } \\
\text { None } \\
1 \text { or more }\end{array}$} & $\mathbf{I}$ & NI & & $\mathbf{I}$ & NI & & I & NI & & I & NI \\
\hline & $6 \%$ & $2 \%$ & permanent & $50 \%$ & $43 \%$ & zipper & $11 \%$ & $14 \%$ & bottom & $12 \%$ & $12 \%$ \\
\hline & $94 \%$ & $98 \%$ & removable & $48 \%$ & $55 \%$ & Velcro & $4 \%$ & $10 \%$ & front & $31 \%$ & $35 \%$ \\
\hline & & & & & & snap & $22 \%$ & $23 \%$ & side & $43 \%$ & $33 \%$ \\
\hline mean & 2.3 & 2.5 & & & & buckle & $62 \%$ & $53 \%$ & top & $14 \%$ & $19 \%$ \\
\hline \multirow[t]{5}{*}{ Claymore } & I & NI & & I & NI & & I & NI & & $\mathbf{I}$ & NI \\
\hline & $16 \%$ & $12 \%$ & permanent & $43 \%$ & $31 \%$ & zipper & $17 \%$ & $15 \%$ & bottom & $8 \%$ & $13 \%$ \\
\hline & $84 \%$ & $88 \%$ & removable & $56 \%$ & $67 \%$ & Velcro & $8 \%$ & $13 \%$ & front & $35 \%$ & $29 \%$ \\
\hline & & & & & & snap & $23 \%$ & $24 \%$ & side & $25 \%$ & $37 \%$ \\
\hline & 1.2 & 1.6 & & & & buckle & $52 \%$ & $47 \%$ & top & $32 \%$ & $21 \%$ \\
\hline Small Utility & $\mathbf{I}$ & NI & & I & NI & & $\mathbf{I}$ & NI & & $\mathbf{I}$ & NI \\
\hline None & $10 \%$ & $5 \%$ & permanent & $65 \%$ & $59 \%$ & zipper & $14 \%$ & $17 \%$ & bottom & $7 \%$ & $9 \%$ \\
\hline \multirow[t]{2}{*}{1 or more } & $90 \%$ & $95 \%$ & removable & $33 \%$ & $40 \%$ & Velcro & $7 \%$ & $14 \%$ & front & $46 \%$ & $37 \%$ \\
\hline & & & & & & snap & $29 \%$ & $27 \%$ & side & $31 \%$ & $33 \%$ \\
\hline mean & 2.1 & 2.1 & & & & buckle & $50 \%$ & $42 \%$ & top & $15 \%$ & $21 \%$ \\
\hline Large Utility & $\mathbf{I}$ & NI & & $\mathbf{I}$ & NI & & $\mathbf{I}$ & NI & & $\mathbf{I}$ & NI \\
\hline None & $13 \%$ & $7 \%$ & permanent & $67 \%$ & $63 \%$ & zipper & $14 \%$ & $18 \%$ & bottom & $25 \%$ & $25 \%$ \\
\hline \multirow[t]{2}{*}{1 or more } & $87 \%$ & $93 \%$ & removable & $32 \%$ & $36 \%$ & Velcro & $5 \%$ & $11 \%$ & front & $32 \%$ & $27 \%$ \\
\hline & & & & & & snap & $22 \%$ & $22 \%$ & side & $22 \%$ & $19 \%$ \\
\hline mean & 1.7 & 1.8 & & & & buckle & $59 \%$ & $49 \%$ & top & $21 \%$ & $28 \%$ \\
\hline Mortar (60mm) & $\mathbf{I}$ & NI & & $\mathbf{I}$ & NI & & $\mathbf{I}$ & NI & & $\mathbf{I}$ & NI \\
\hline None & $45 \%$ & $44 \%$ & permanent & $24 \%$ & $22 \%$ & zipper & $8 \%$ & $10 \%$ & bottom & $11 \%$ & $17 \%$ \\
\hline \multirow[t]{2}{*}{1 or more } & $55 \%$ & $56 \%$ & removable & $74 \%$ & $77 \%$ & Velcro & $6 \%$ & $11 \%$ & front & $16 \%$ & $22 \%$ \\
\hline & & & & & & snap & $22 \%$ & $22 \%$ & side & $40 \%$ & $33 \%$ \\
\hline mean & 1.0 & 0.9 & & & & buckle & $64 \%$ & $57 \%$ & top & $32 \%$ & $28 \%$ \\
\hline
\end{tabular}

\begin{tabular}{|c|c|c|c|c|c|c|c|c|c|c|c|}
\hline \multirow{4}{*}{ 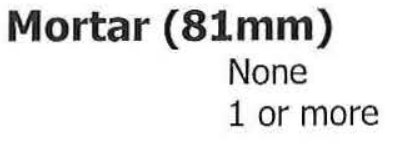 } & $\mathbf{I}$ & NI & & $\mathbf{I}$ & NI & & I & NI & & $\mathbf{I}$ & $\mathbf{N I}$ \\
\hline & $56 \%$ & $54 \%$ & permanent & $22 \%$ & $22 \%$ & zipper & $8 \%$ & $10 \%$ & bottom & $12 \%$ & $18 \%$ \\
\hline & $44 \%$ & $46 \%$ & removable & $77 \%$ & $77 \%$ & Velcro & $6 \%$ & $10 \%$ & front & $18 \%$ & $20 \%$ \\
\hline & & & & & & snap & $22 \%$ & $22 \%$ & side & $36 \%$ & $32 \%$ \\
\hline mean & 0.7 & 0.7 & & & & buckle & $64 \%$ & $57 \%$ & top & $34 \%$ & $29 \%$ \\
\hline ileep System & $\mathbf{I}$ & NI & & $\mathbf{I}$ & NI & & $\mathbf{I}$ & NI & & I & NI \\
\hline None & $22 \%$ & $12 \%$ & permanent & $39 \%$ & $30 \%$ & zipper & $22 \%$ & $20 \%$ & bottom & $76 \%$ & $59 \%$ \\
\hline 1 or more & $78 \%$ & $88 \%$ & removable & $59 \%$ & $69 \%$ & Velcro & $3 \%$ & $9 \%$ & front & $2 \%$ & $3 \%$ \\
\hline & & & & & & snap & $15 \%$ & $14 \%$ & side & $1 \%$ & $2 \%$ \\
\hline mean & 0.8 & 0.9 & & & & buckle & $59 \%$ & $56 \%$ & top & $21 \%$ & $36 \%$ \\
\hline
\end{tabular}

*Missing data will account for remaining percent 
Should a load carriage system have a tube hydration system? (e.g. a CamelBak) Infantry

Yes

$88 \%$ Non-Infantry

$89 \%$

Of those who selected "yes"...

Does it need to be NBC capable?

Yes

$88 \% \quad 89 \%$

How should it be carried? (Check all that apply)

In a pocket inside the patrol pack $\quad 39 \% \quad 32 \%$

Under the main ruck flap $\quad 27 \% \quad 19 \%$

In a pocket inside the LBV $\quad 35 \% \quad 34 \%$

Between user's back and main ruck $31 \% \quad 38 \%$

In a separate carrier $\quad 30 \% \quad 26 \%$

Other $11 \% \quad 8 \%$

Of those who selected "yes" and "in a separate carrier"...

Should it be able to attach to the outside of the main ruck?

Yes $\quad 87 \% \quad 89 \%$

Should it be able to attach to the outside of the patrol pack?

Yes $\quad 86 \% \quad 90 \%$

Should it be able to attach to the load bearing vest (LBV)?

Yes $86 \% \quad 89 \%$

Should a load carriage system have a detachable patrol pack?

Yes $\quad 88 \% \quad 93 \%$ 
Of those who selected "yes"...

Should the patrol pack have a waist strap?

$\begin{array}{lll} & \text { Infantry } & \text { Non-Infantry } \\ \text { Yes } & 56 \% & 66 \%\end{array}$

What type of equipment should Marines use to carry a fighting load?

Cartridge belt with suspender

$22 \%$

$15 \%$

Vest rig design

$27 \%$

$26 \%$

Modular vest rig design

$29 \%$

$44 \%$

Chest harness

$5 \%$

Modular chest harness

$17 \%$

$2 \%$

$13 \%$

What type of pockets should a load bearing vest have? (Fill in chart below)

How Many

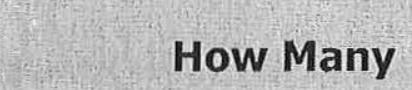

First Aid

Double 30 round

$\begin{array}{llllll} & \mathbf{I} & \mathbf{N I} & & \mathbf{I} & \mathbf{N I} \\ \text { none } & 5 \% & 3 \% & \text { permanent } & 28 \% & 30 \% \\ \begin{array}{l}1 \text { or more } \\ \text { mean }\end{array} & 95 \% & 97 \% & \text { removable } & 70 \% & 69 \% \\ & 1.1 & 1.2 & & & \end{array}$

Triple 30 round

$\begin{array}{llllll} & \text { I } & \text { NI } & & \text { I } & \text { NI } \\ \text { none } & 33 \% & 28 \% & \text { permanent } & 23 \% & 28 \% \\ 1 \text { or more } & 67 \% & 72 \% & \text { removable } & 74 \% & 71 \% \\ \text { mean } & 1.6 & 1.7 & & & \end{array}$




$\begin{array}{lllllll}\text { Utility/Canteen } & & \mathbf{I} & \mathbf{N I} & & \mathbf{I} & \mathbf{N I} \\ & \text { none } & 10 \% & 10 \% & \text { permanent } & 19 \% & 23 \% \\ & 1 \text { or more } & 90 \% & 90 \% & \text { removable } & 80 \% & 76 \% \\ & \text { mean } & 1.8 & 1.8 & & & \end{array}$

$\begin{array}{lllllll}2 \text { quart canteen } & & \mathbf{I} & \mathbf{N I} & & & \\ & \text { none } & 46 \% & 38 \% & \text { permanent } & 10 \% & 13 \% \\ & 1 \text { or more } & 54 \% & 62 \% & \text { removable } & 88 \% & 85 \% \\ & \text { mean } & 0.7 & 0.9 & & & \end{array}$

$\begin{array}{cllllc}\text { Fragmentation Grenade } & \text { I } & \text { NI } & & \text { I } & \text { NI } \\ \text { none } & 2 \% & 2 \% & \text { permanent } & 24 \% & 31 \% \\ 1 \text { or more } & 98 \% & 98 \% & \text { removable } & 74 \% & 67 \% \\ \text { mean } & 2.8 & 3.0 & & & \end{array}$

Smoke grenade

$\begin{array}{lllllc} & \mathbf{I} & \mathbf{N I} & & \mathbf{I} & \mathbf{N I} \\ \text { none } & 19 \% & 16 \% & \text { permanent } & 15 \% & 22 \% \\ \text { 1 or more } & 81 \% & 84 \% & \text { removable } & 83 \% & 77 \% \\ \text { mean } & 1.5 & 1.6 & & & \end{array}$

$40 \mathrm{~mm}$ grenade

$\begin{array}{lllllc} & \mathbf{I} & \mathbf{N I} & & \mathbf{I} & \mathbf{N I} \\ \text { none } & 23 \% & 31 \% & \text { permanent } & 10 \% & 15 \% \\ 1 \text { or more } & 77 \% & 69 \% & \text { removable } & 88 \% & 83 \% \\ \text { mean } & 6.2 & 3.9 & & & \end{array}$

$\begin{array}{rllllc}\text { Single 9mm magazine } & \text { I } & \text { NI } & & \text { I } & \text { NI } \\ \text { none } & 38 \% & 30 \% & \text { permanent } & 9 \% & 17 \% \\ 1 \text { or more } & 62 \% & 70 \% & \text { removable } & 89 \% & 81 \% \\ \text { mean } & 1.5 & 1.8 & & & \end{array}$




$\begin{array}{rllllc}\text { Double 9mm magazine } & \mathbf{I} & \text { NI } & & \mathbf{I} & \text { NI } \\ \text { none } & 43 \% & 29 \% & \text { permanent } & 7 \% & 15 \% \\ 1 \text { or more } & 57 \% & 71 \% & \text { removable } & 89 \% & 84 \% \\ \text { mean } & 1.2 & 1.6 & & & \end{array}$

$\begin{array}{rllllc}\text { M9 service pistol holster } & \text { I } & \text { NI } & & \text { I } & \text { NI } \\ \text { none } & 27 \% & 17 \% & \text { permanent } & 4 \% & 8 \% \\ 1 \text { or more } & 73 \% & 83 \% & \text { removable } & 94 \% & 90 \% \\ \text { mean } & 0.7 & 0.8 & & & \end{array}$

What kind of carrying equipment is best suited for short (e.g. less than 24 hours) combat missions?

Patrol Pack

Butt Pack

Both

Neither

\section{Infantry}

$35 \%$

$23 \%$

$40 \%$

$2 \%$
Non-Infantry

$43 \%$

$18 \%$

$37 \%$

$2 \%$

What items would you carry in your butt pack or assault pack for a 12-24 hour mission?

$\begin{array}{llllll}\text { MRE } & \text { Infantry } & \text { Non-Infantry } & & \text { Infantry } & \text { Non-Infantry } \\ \text { poncho } & 96 \% & 95 \% & \text { flex cuffs } & 55 \% & 41 \% \\ \text { Gortex top } & 73 \% & 66 \% & \text { sand bags } & 17 \% & 7 \% \\ \text { Gortex bottom } & 40 \% & 40 \% & \text { electrical tape } & 75 \% & 62 \% \\ \text { polypro top } & 12 \% & 19 \% & \text { collapsible litter } & 14 \% & 6 \% \\ \text { polypro bottom } & 11 \% & 29 \% & \text { foot powder } & 43 \% & 46 \% \\ \text { black utility gloves } 77 \% & 14 \% & \text { hygiene gear } & 27 \% & 38 \% \\ \text { extra socks } & 78 \% & 83 \% & \text { sewing kit } & 22 \% & 17 \% \\ \text { knit cap } & 58 \% & 53 \% & \text { cammie paint } & 91 \% & 85 \% \\ \text { flashlight } & 81 \% & 78 \% & \text { bug repellent } & 61 \% & 63 \% \\ \text { signal mirror } & 63 \% & 50 \% & \text { extra ammo } & 73 \% & 75 \% \\ \text { 550 chord } & 93 \% & 84 \% & \text { weapon cleaning gear } 84 \% & 71 \% \\ \end{array}$


Which Load Carrying System are you using now?

$\begin{array}{lll}\text { Pack } & \text { Infantry } & \text { Non-Infantry } \\ \text { Large ALICE Pack } & 22 \% & 14 \% \\ \text { Medium ALICE Pack } & 9 \% & 40 \% \\ \text { MOLLE I } & 6 \% & 4 \% \\ \text { MOLLE II } & 60 \% & 34 \% \\ \text { Lowe Vector Pack } & 3 \% & 3 \%\end{array}$

Which Load Carrying System are you using now?

\section{Combat Load}

ALICE Pistol Belt and Suspenders $\quad 15 \% \quad 24 \%$

Tactical Load Bearing Vest (LBV) $\quad 10 \% \quad 26 \%$

Enhanced LBV $\quad 6 \% \quad 7 \%$

MOLLE I Vest $\quad 10 \% \quad 6 \%$

MOLLE II FLC $\quad 60 \% \quad 33 \%$

Overall, how many years of experience do you have with your currently issued system? Mean

3.2years

4.4 years

Do you have a problem employing individual weapons with your current system?

Yes

$35 \%$

$27 \%$

Of those who selected "yes"...

Which ones? (check all that apply)

M16A2

$68 \%$

$76 \%$

M16A2 w/M203 Grenade Launcher

M4

$43 \%$

$20 \%$

M4 w/M203 Grenade Launcher

$9 \%$

$5 \%$

$9 \%$

$4 \%$

$9 \mathrm{~mm}$

M249 SAW

$28 \%$

$32 \%$

$39 \%$

$18 \%$

Of those who selected "yes" and "M16A2"... 
What are the basic problems with the M16A2? (check all that apply)

Carrying - sling/pack

Carrying - arm movement

Operating weapon - arm movement

Operating weapon - shoulder

Unable to lift head in prone

Unable to attain a stock weld

Other
$81 \%$

$64 \%$

$56 \%$

$65 \%$

$70 \%$

$56 \%$

$25 \%$
$82 \%$

$57 \%$

$44 \%$

$64 \%$

$61 \%$

$53 \%$

$13 \%$

Of those who selected "yes" and "M16A2 w/M203 Grenade Launcher"...

\section{What are the basic problems with the M16A2 with M203 Grenade Launcher?}

$\begin{array}{lll}\text { Carrying - arm movement } & 73 \% & 71 \% \\ \text { Operating weapon -arm movement } & 63 \% & 59 \% \\ \text { Operating weapon - shoulder } & 69 \% & 65 \% \\ \text { Unable to lift head in prone } & 72 \% & 59 \% \\ \text { Unable to attain a stock weld } & 59 \% & 54 \% \\ \text { Other } & 27 \% & 17 \%\end{array}$

Of those who selected "yes" and "M4"...

$\begin{array}{lcc}\text { What are the basic problems with the M4? } & \\ \text { Carrying - sling/pack } & 60 \% & 50 \% \\ \text { Carrying - arm movement } & 72 \% & 75 \% \\ \text { Operating weapon - arm movement } & 55 \% & 50 \% \\ \text { Operating weapon - shoulder } & 67 \% & 57 \% \\ \text { Unable to lift head in prone } & 72 \% & 55 \% \\ \text { Unable to attain a stock weld } & 65 \% & 52 \% \\ \text { Other } & 37 \% & 14 \%\end{array}$

Of those who selected "yes" and "M4 w/M203 Grenade Launcher"...

What are the basic problems with the M4 with M203 Grenade Launcher?

$\begin{array}{lll}\text { Carrying - arm movement } & 70 \% & 66 \% \\ \text { Operating weapon - arm movement } & 68 \% & 61 \% \\ \text { Operating weapon - shoulder } & 71 \% & 66 \% \\ \text { Unable to lift head in prone } & 73 \% & 57 \% \\ \text { Unable to attain a stock weld } & 71 \% & 61 \% \\ \text { Other } & 44 \% & 23 \%\end{array}$

Of those who selected "yes" and "9mm"... 
What are the basic problems with the $9 \mathrm{~mm}$ ?

$\begin{array}{lll}\text { Carrying - arm movement } & 42 \% & 37 \% \\ \text { Carrying - belt } & 79 \% & 78 \% \\ \text { Operating weapon - arm movement } & 28 \% & 27 \% \\ \text { Operating weapon - holster } & 77 \% & 74 \% \\ \text { Unable to lift head in prone } & 32 \% & 28 \% \\ \text { Unable to attain a stock weld } & 13 \% & 7 \% \\ \text { Other } & 23 \% & 17 \%\end{array}$

Of those who selected "yes" and "M249 SAW"...

What are the basic problems with the M249 SAW?

Carrying - arm movement $\quad 76 \% \quad 66 \%$

Operating weapon - arm movement $\quad 68 \% \quad{ }^{\prime} 62 \%$

Operating weapon - shoulder $\quad 68 \% \quad 66 \%$

Unable to lift head in prone $\quad 74 \% \quad 66 \%$

Unable to attain a stock weld $\quad 60 \% \quad 56 \%$

Other $27 \% \quad 20 \%$

$\begin{array}{lcc}\text { What kind of body armor are you currently using. Select one answer. } \\ \text { Interceptor } & 81 \% & 46 \% \\ \text { PASGT } & 19 \% & 49 \%\end{array}$

Of those who selected "Interceptor"...

Do you ever attach pockets or pouches to the webbing on Interceptor?

Yes

$53 \%$

$50 \%$

Of those who selected "Interceptor" and "yes"...

\section{Which ones?}

ammo pouches

first aid kit

$94 \% \quad 87 \%$

canteen / utility

grenade

$41 \%$

$27 \%$

$47 \%$

$38 \%$

knife/bayonet

$60 \%$

$39 \%$

$46 \% \quad 57 \%$ 
Do you have any compatibility problems between your body armor (flack jacket) and the load carrying system?

Yes

$48 \%$ $46 \%$

Of those who selected "yes"...

Which ones? (Check all that apply)

Uncomfortable at the shoulder

Pack rides poorly

$70 \%$

$69 \%$

$49 \%$

$24 \%$

$71 \%$

$30 \%$
$69 \%$

$68 \%$

$48 \%$

$12 \%$

$70 \%$

$21 \%$

Can features of your current system be improved to make it more suitable for Marines? Yes $79 \%$ $79 \%$

Of those who selected "yes"...

What areas need to be addressed?

Modularity

Main pack size

Main pack height

Main pack width

Adjustability

Frame height

Frame width

Improve durability

Change layout of system
(Check all that apply)

\section{Infantry}

$41 \%$

$42 \%$

$26 \%$

$24 \%$

$51 \%$

$26 \%$

$18 \%$

$76 \%$

$66 \%$
Non-Infantry

$40 \%$

$42 \%$

$22 \%$

$20 \%$

$57 \%$

$22 \%$

$14 \%$

$64 \%$

$59 \%$ 


\section{Current system is...}

Of those who selected "modularity"... Of those who selected "main pack size"... Of those who selected "main pack height"... Of those who selected "main pack width"... Of those who selected "adjustability"... Of those who selected "frame height"... Of those who selected "frame width"...

$\begin{array}{llllll} & \text { I } & \text { NI } & & \text { I } & \text { NI } \\ \text { too modular } & 52 \% & 26 \% & \text { not modular enough } & 47 \% & 74 \% \\ \text { too big } & 37 \% & 21 \% & \text { too small } & 62 \% & 79 \% \\ \text { too long } & 53 \% & 38 \% & \text { too short } & 47 \% & 62 \% \\ \text { too wide } & 58 \% & 34 \% & \text { not wide enough } & 42 \% & 66 \% \\ \text { too adjustable } & 28 \% & 11 \% & \text { not adjustable enough } & 72 \% & 89 \% \\ \text { too long } & 77 \% & 61 \% & \text { too short } & 21 \% & 38 \% \\ \text { too wide } & 67 \% & 44 \% & \text { too narrow } & 31 \% & 56 \%\end{array}$


Appendix B.

Screen Shots of Website 


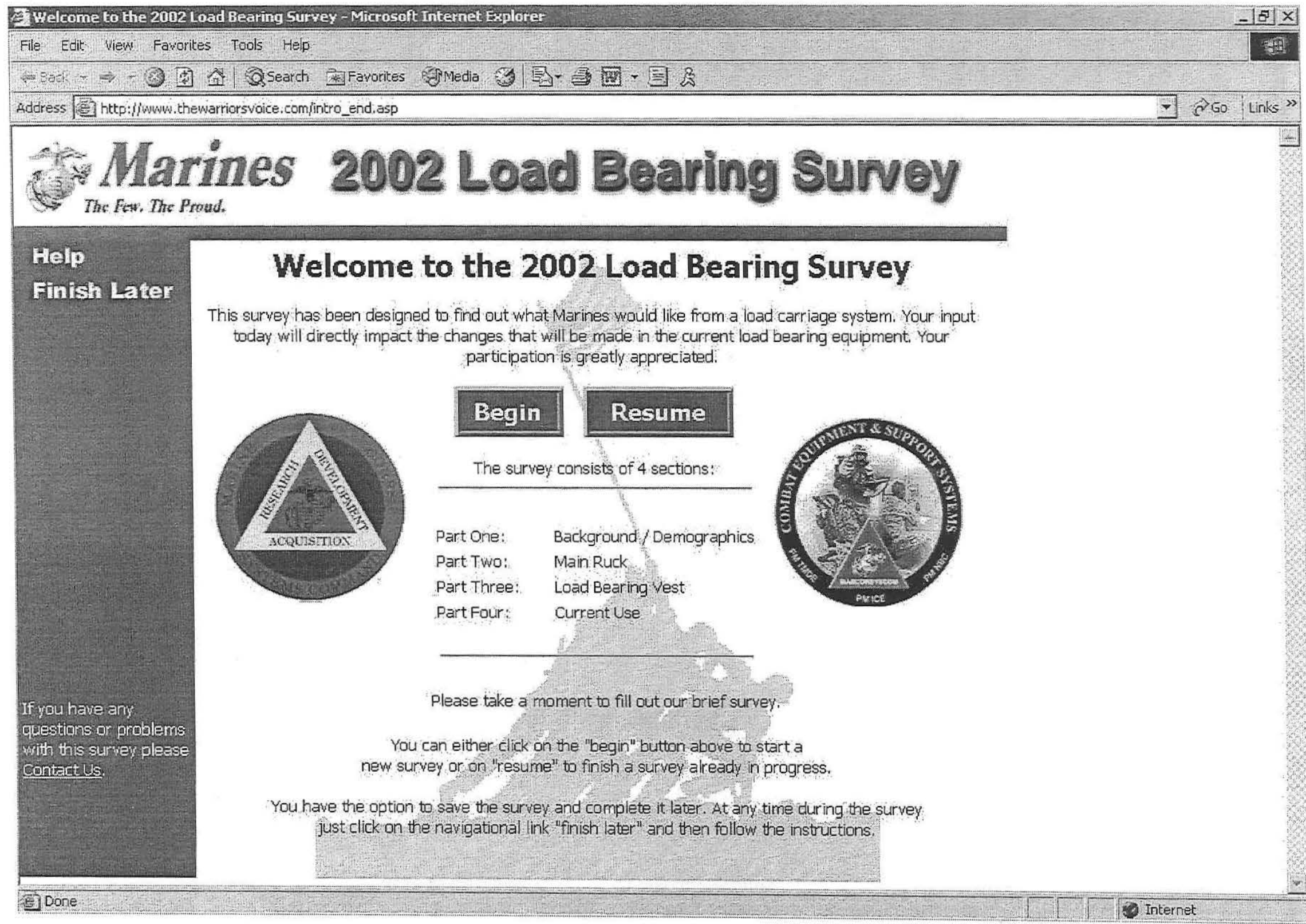




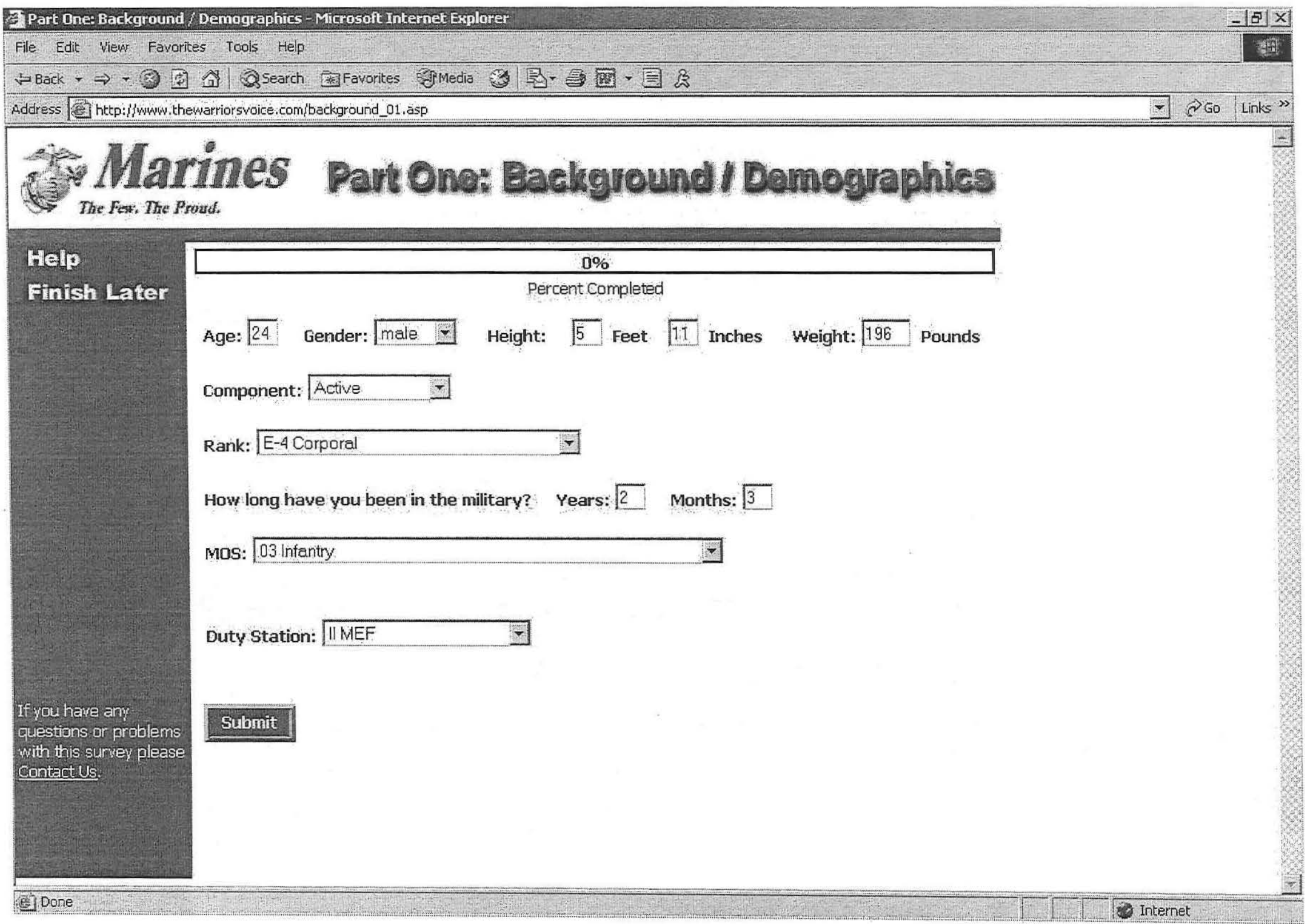


File Edit Viem Favorites Tools He

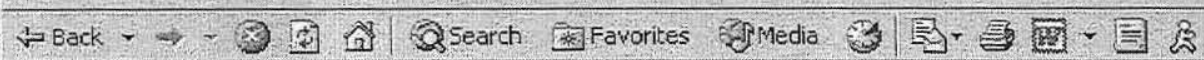

\section{Warines Part Ono: Background I Domographics}

Help

Finish Later

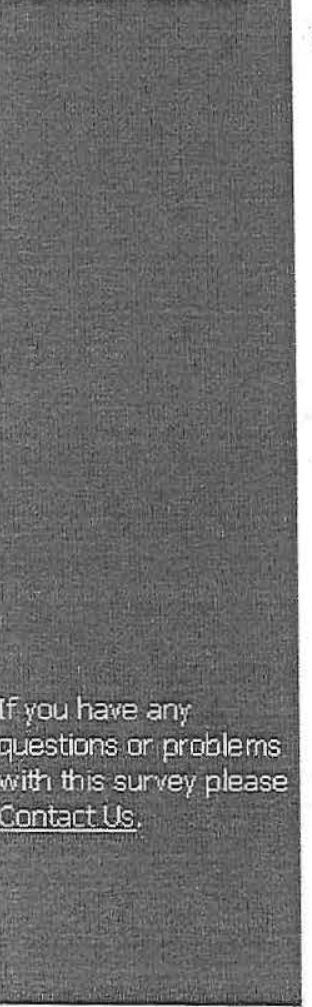

$5 \%$

Percent Completed

Weapon Carried (check your current issued weapon(s))

VM16A2

ГM1642 with M203 Grenade Launcher

ГM4

CM4 with M203 Grenade Launcher

$\square 9 \mathrm{~mm}$

ГM249 SAW

Submit 
File Edit View Favorites Tools Help

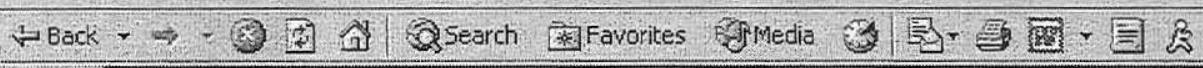

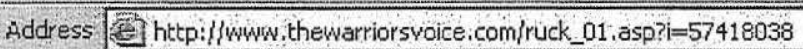

\section{Aarines Part Two: Main Ruck \\ The Few, The Proud.}

Help

Finish Later

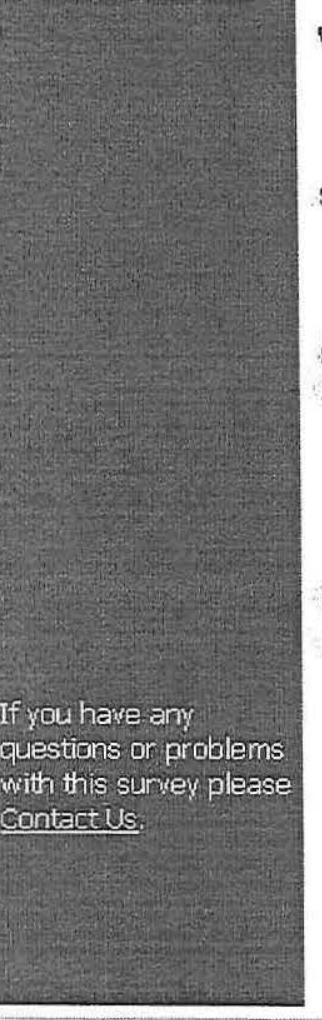

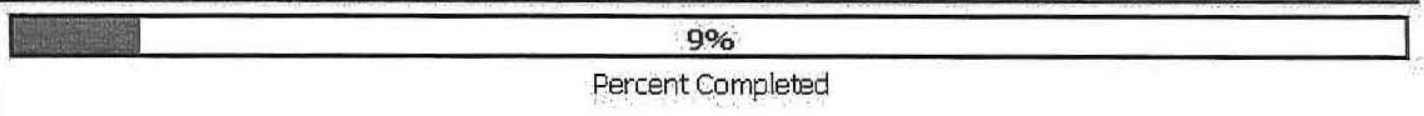

What type of frame is best suited for a load carriage system?

6. External (the frame is located outside the main ruck and can be separated from it)

O Internal (the frame is located inside of the main ruck and cannot be separated from it)

Should you be able to carry the pack without the frame attached?

CYes

6 No

Should the frame have a stand-alone capability? (e.g. you can carry MRE cases, ammunition, or 5 gallon water cans on it)

o yes.

CNO

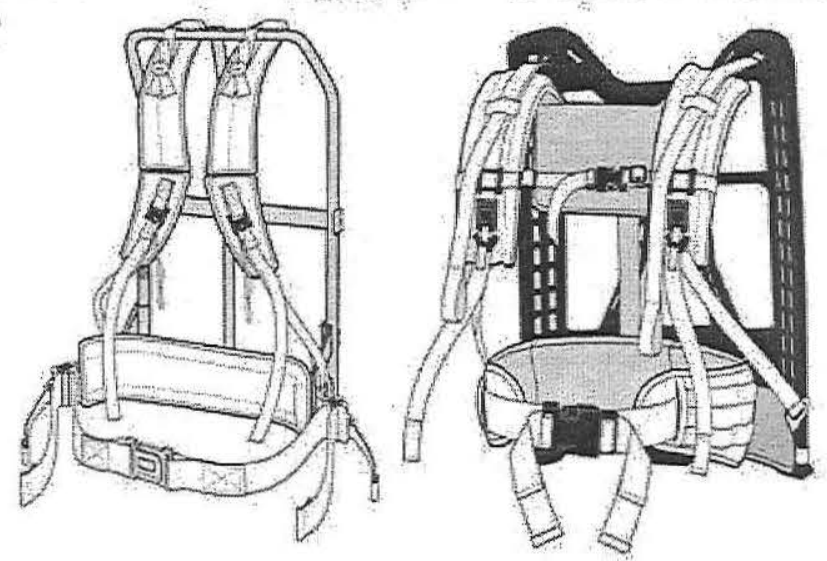

Examples of External Frame 


\section{Farines Part Two: Main Ruck}

The Fis, The Prowd.

\section{Help}

Finish Later

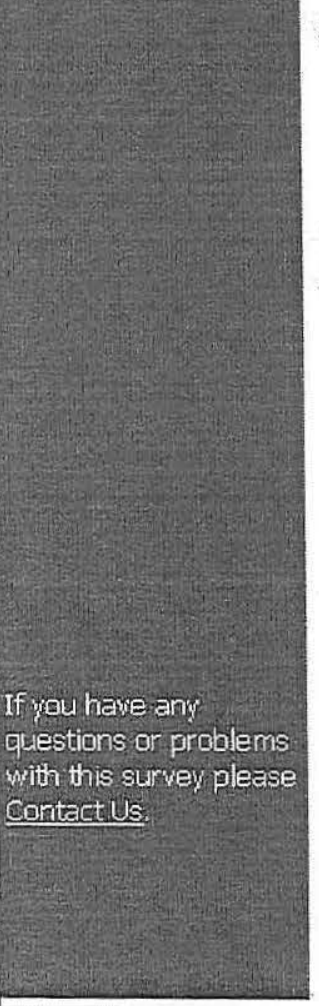

$14 \%$

Percent Completed

Should the pack have different size frames, or one size fits all (adjustable)?

$C$ Different frame sizes (small; medium, and large)

6 one size fits all (adjustable) 


\section{Marines Part Two: Main Ruek}

The Few. The Proud.

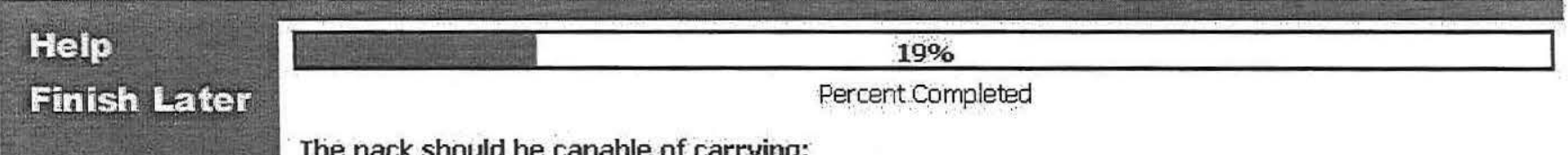

The pack should be capable of carrying:

Main Ruck along with any items that you would attach to the outside of the ruck (example:

machine gun or mortar base plate attached to outside)

$$
100 \Rightarrow \text { pounds }
$$

Patrol Pack:

30. pounds

Total system weight carrying capability: 130 pounds.

Submit

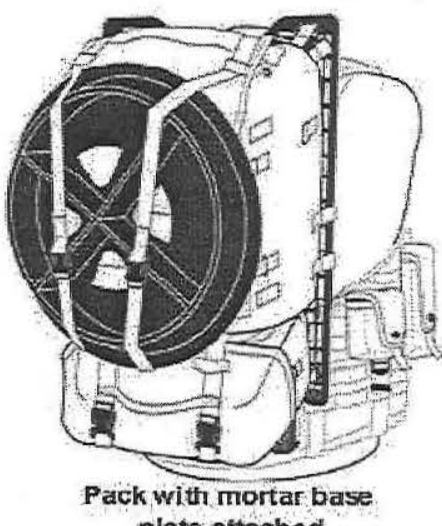

plate attached

If you have any

auestions or problems

with this survey please

Contact Us.

Pack with mortar base
plate attached




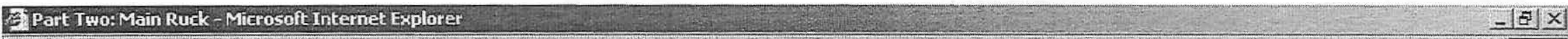

File Edit Viein Favorites Tools Help At

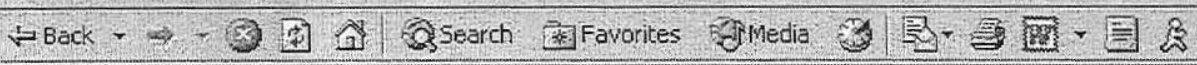

Address $\vartheta 7$ hitp://www.thewarriorsvoice.com/ruck_04.asp?i=57418038

- ¿Go Links Marines Part Two: Main Ruck

The Fes, Tre Prourd

Lele

Fintsh Later

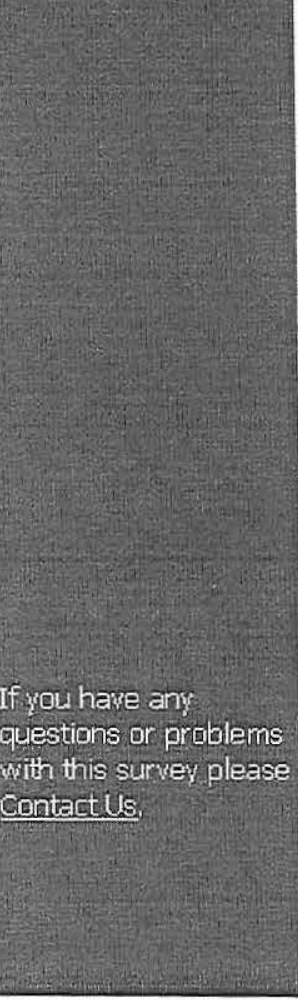

$23 \%$

Percent Completed

Approximately how many cubic inches should the pack hold?

Please Note: MOLLE (includes the main pack, sustainment 5200 cubic inches

pouches and sleep system carrier)

Large ALICE:

Medium ALICE

MOLLE Patrol Pack:

3900 cubic inches

2250 cubie inches

1500 cubic inches

Main Ruck Sack: Patrol Pack:

$5000-$ cubic inches $\quad 12507$ cubic inches

Total system volume carrying capability: 6250 cubic inches.

Submit 


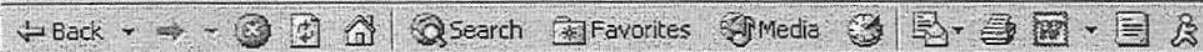

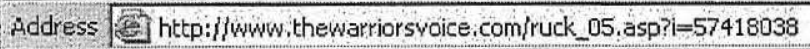

\section{Marines Part Two: Main Ruek \\ The Fes. The Proud.}

\section{Help}

Finish Later
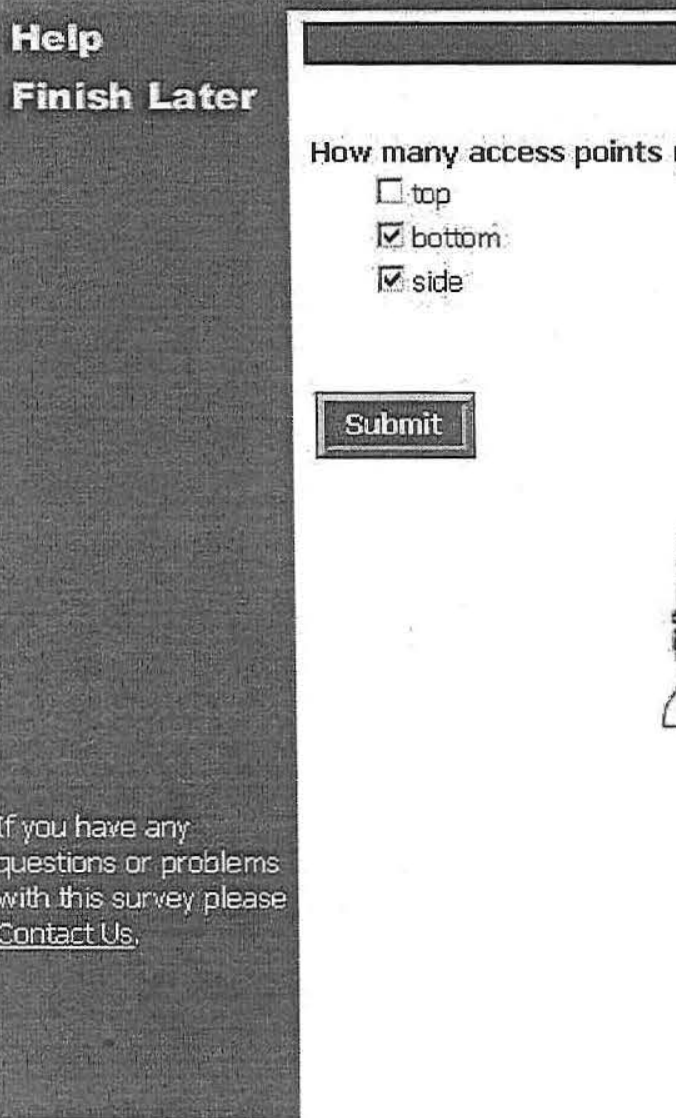

How many access points (openings) should the pack have?

[top

$\sqrt{ }$ bottom

V side

Submit

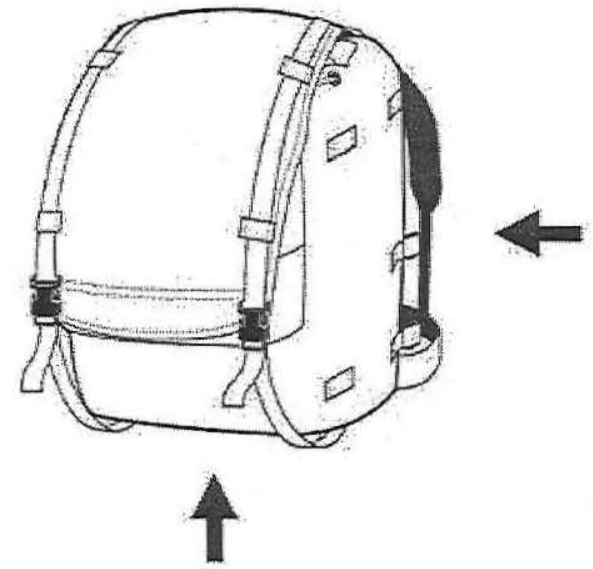




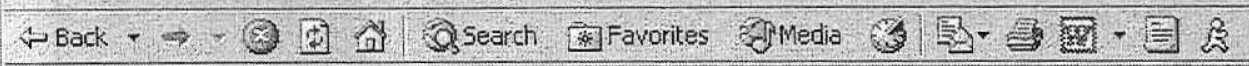

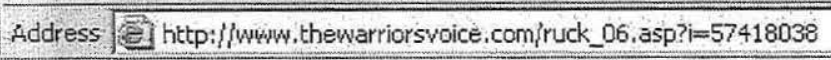

\section{Marines Part Two: Main Ruck}

\section{Help}

Inish Later

If you have any

questions or problems

with this surrey please

contect Us:

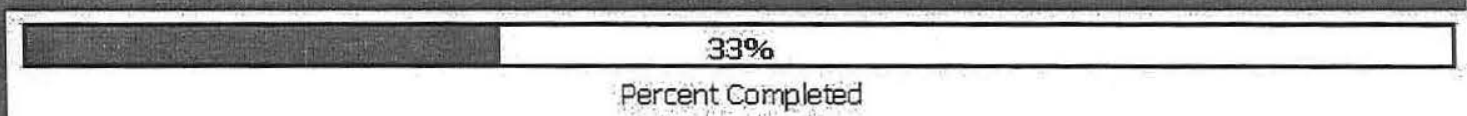

What type of pockets should the main pack have? (Fill in chart below)

\begin{tabular}{|c|c|c|c|c|c|}
\hline & How Many & Attachment & Type of closure & $\begin{array}{c}\text { Placement of Pocket } \\
\text { on Ruck }\end{array}$ & \\
\hline Sustainment & - & 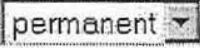 & velcro $>$ & bottom 7 & Next \\
\hline Claymore & \pm & removable $\mathbf{z}$ & snap - & side $\square$ & Next \\
\hline Small Utility & $\nabla$ & removable & velcro - & top & Hext \\
\hline Large Utility & none - & 7 & . & 7 & Wext \\
\hline Mortar (60mm) & 1 & permanent $F$ & snap & bottom $\nabla$ & Next \\
\hline Mortar (81mm) & 3 & removable - & buckle. $=$ & front & Next \\
\hline Sleep System & none $\rightarrow$ & $x$ & $\varnothing$ & $x$ & Submit \\
\hline
\end{tabular}

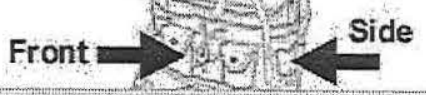




\section{Marines Part Two: Main Ruck \\ The Few. The Proud.}

\section{Help}

Finish Later

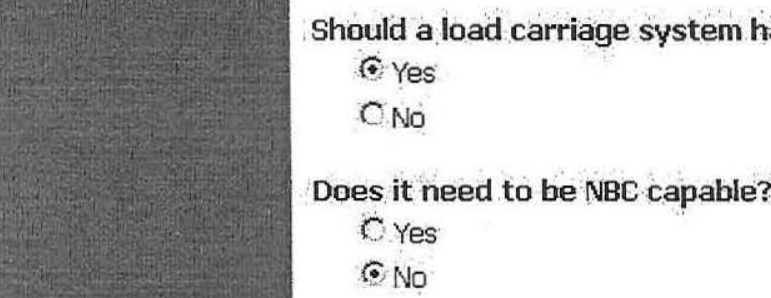

How should it be carried? (Check all that apply) IIn a pocket inside the patrol pack

Tunder the main ruck flap

₹ In a pocket inside the LBV (load bearing vest)

$\Gamma$ Between user's back and main ruck

IIn a separate carrier

$\sqrt{ }$ other

\section{If you hare any:}

questions or problems

with this survey please

contact Us:

\section{Submit}

$38 \%$

Percent Completed

tube hydration system? (e.g.a CamelBak)

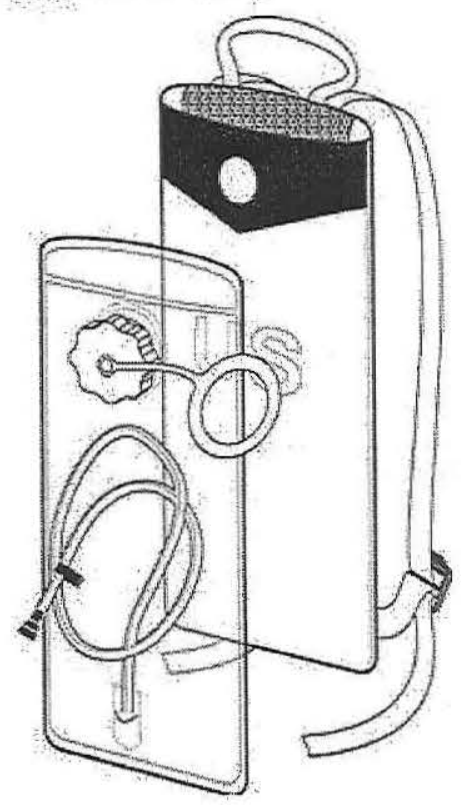


Eart TwosMain Ruck-Microsoft Internet Explarer -10$] x$

File Edit View Favorites Tools Help ted:

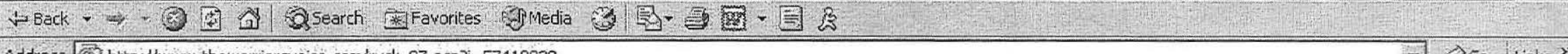

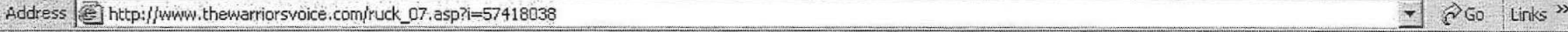

Marines Part Two: Main Ruck

The Few. The Proud.

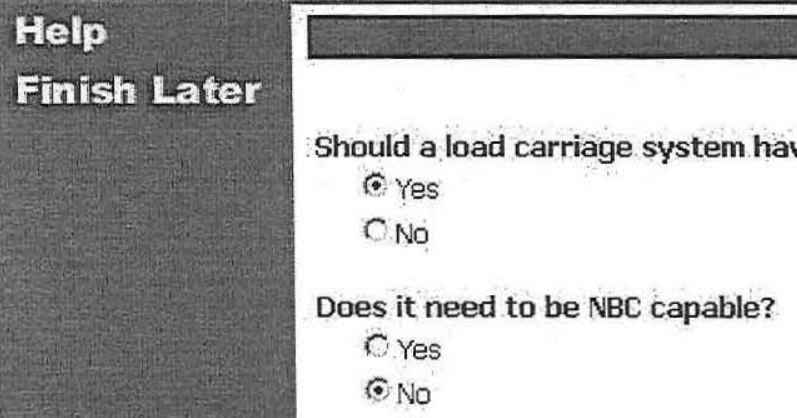

How should it be carried? (Check all that apply)

EIn a pocket inside the patrol pack

$\Gamma$ Under the main ruck flap

VIn a pocket inside the LBV (load bearing vest)

CBetween user's back and main ruck

In a separate carrier

Fr Other

If you have any:

questians or problems

With this surrey alease

contactus

Sulanit
$38 \%$

\section{Percent Completed}

tube hydration system? (e.g. a CamelBak)

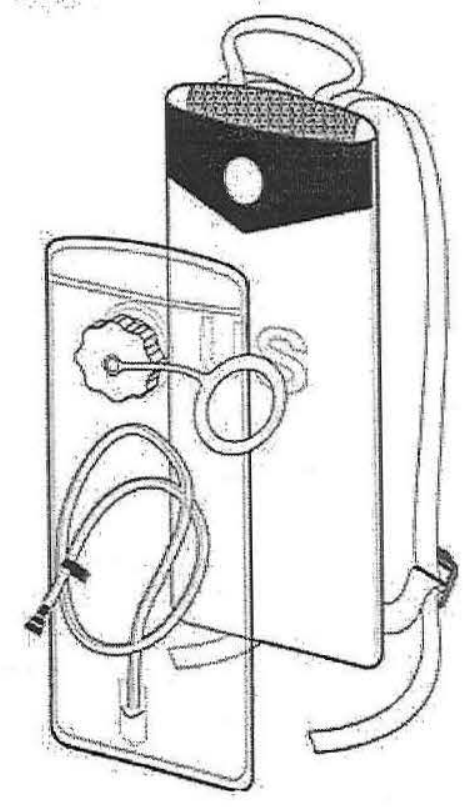




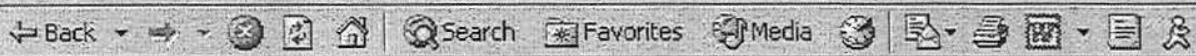

Address 6 http://www.thewarriorsvoice.com/ruck_08.asp?i=57418038.

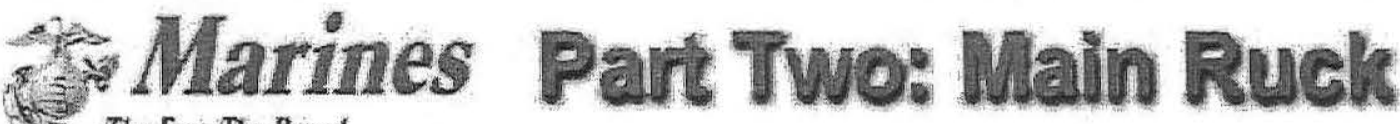

The Few. The Proud.

\section{Help}

Finish Later

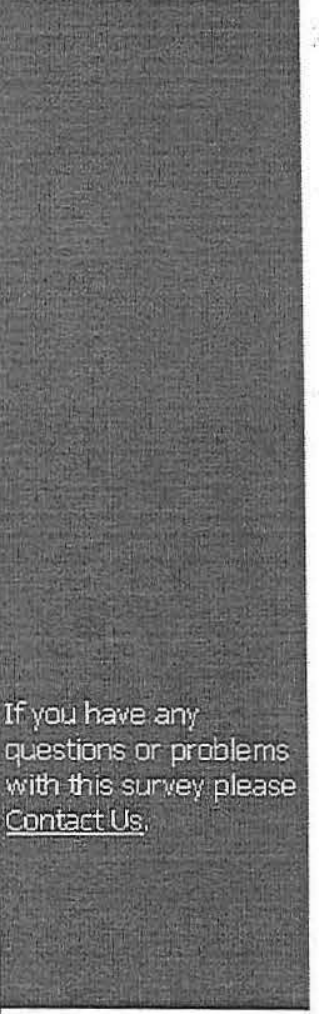

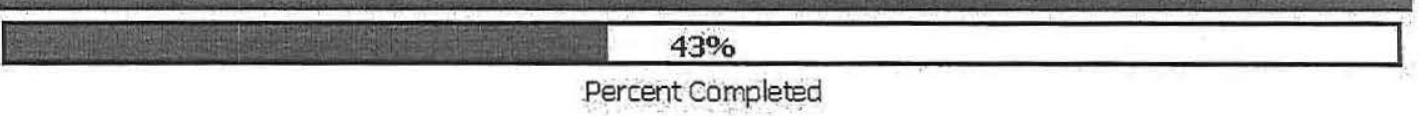

Should a load carriage system have a detachable patrol pack?

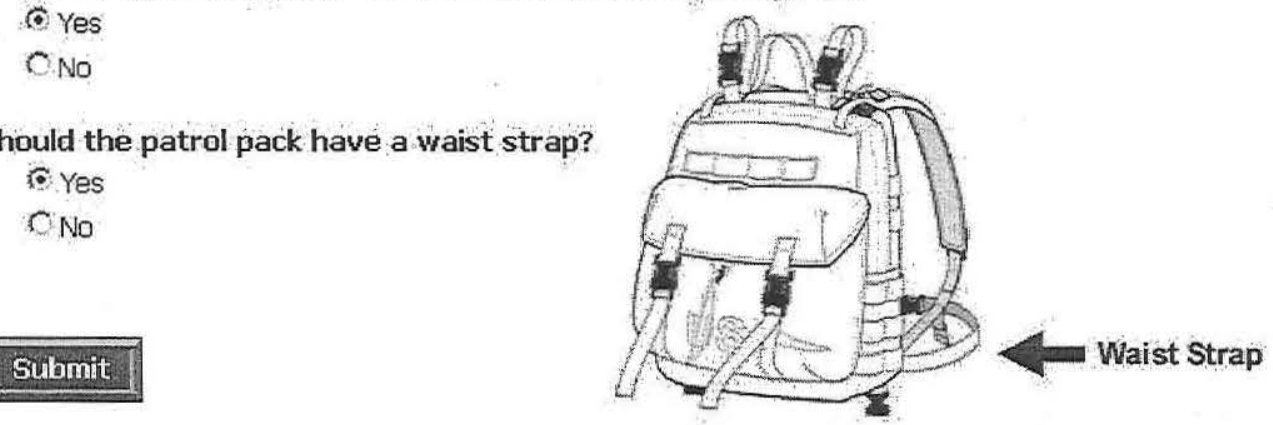




\section{尌 Marines Part Three: Load Bearing Vest}

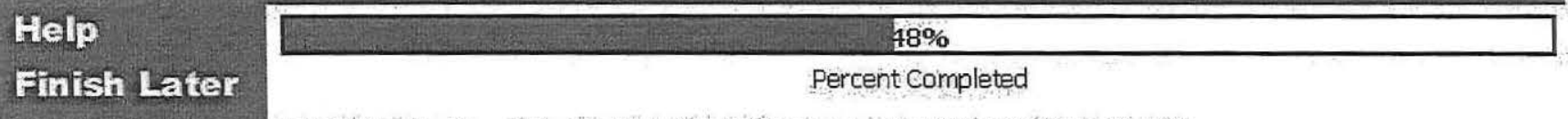

What type of equipment should Marines use to carry a fighting load? c. Cartridge belt with suspender

$C$ vest rig design

$C$ Modular vest rig design

$\checkmark$ chest harness

Modular chest harness

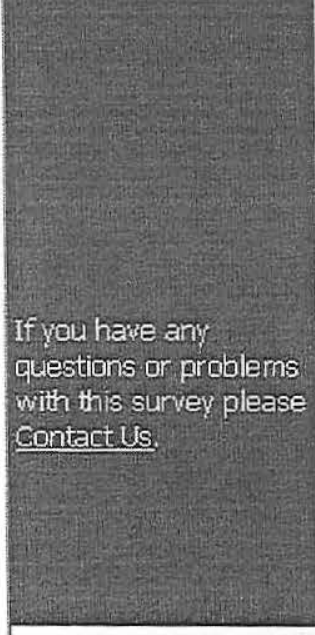

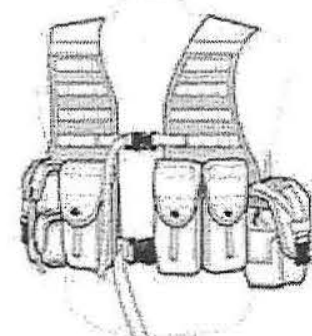

Modular Vest

Rig Design
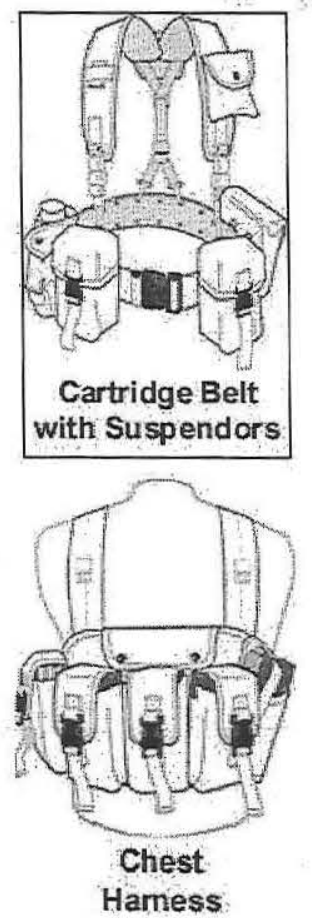
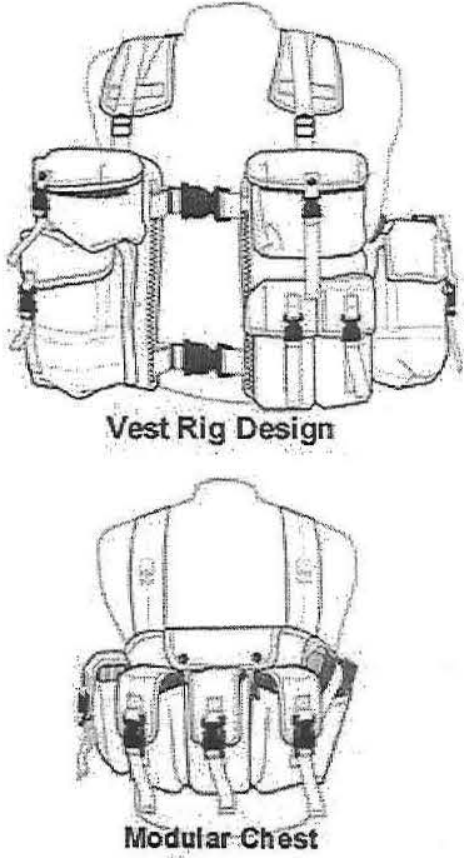

Harness

(Removable Pockets) 


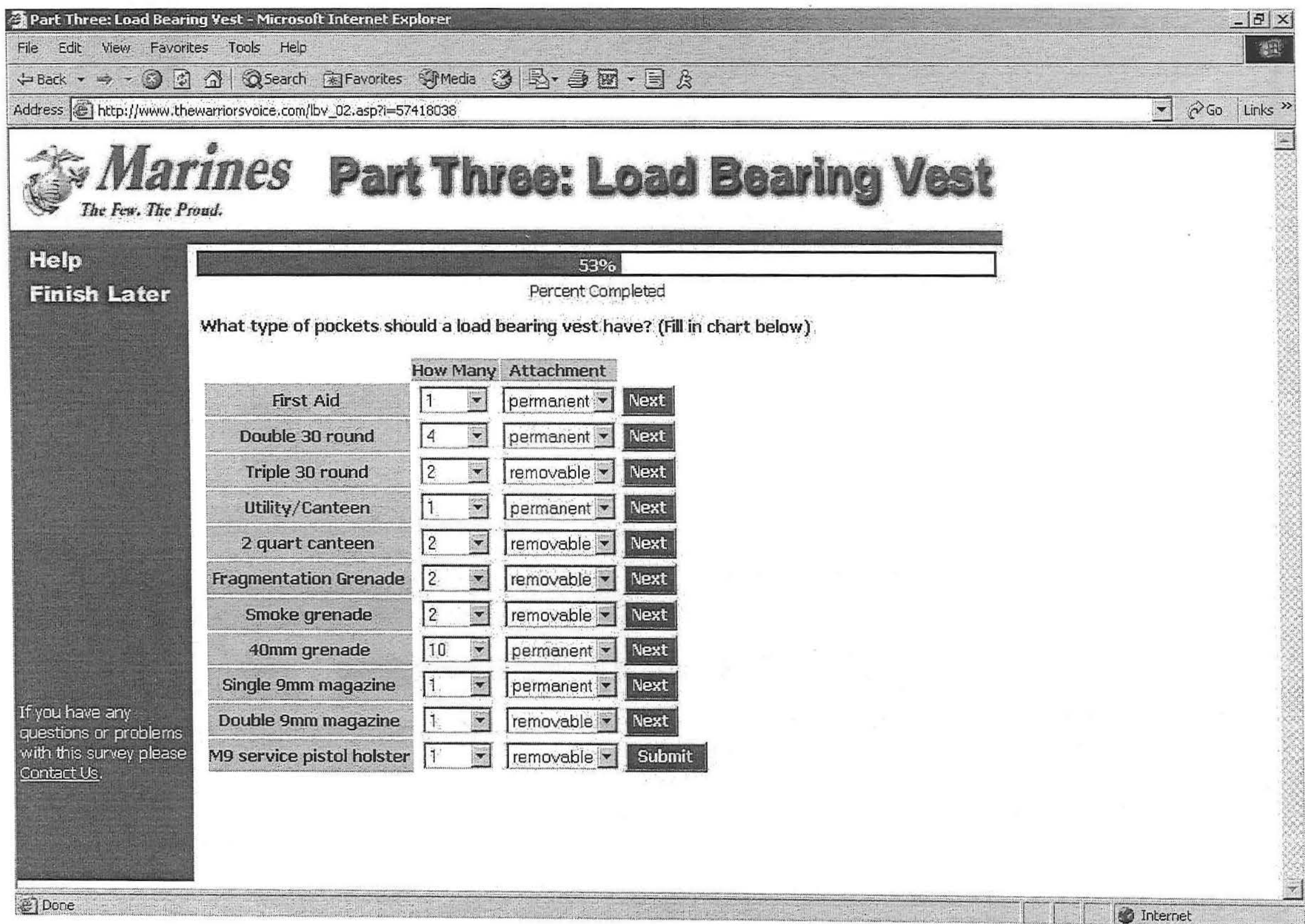




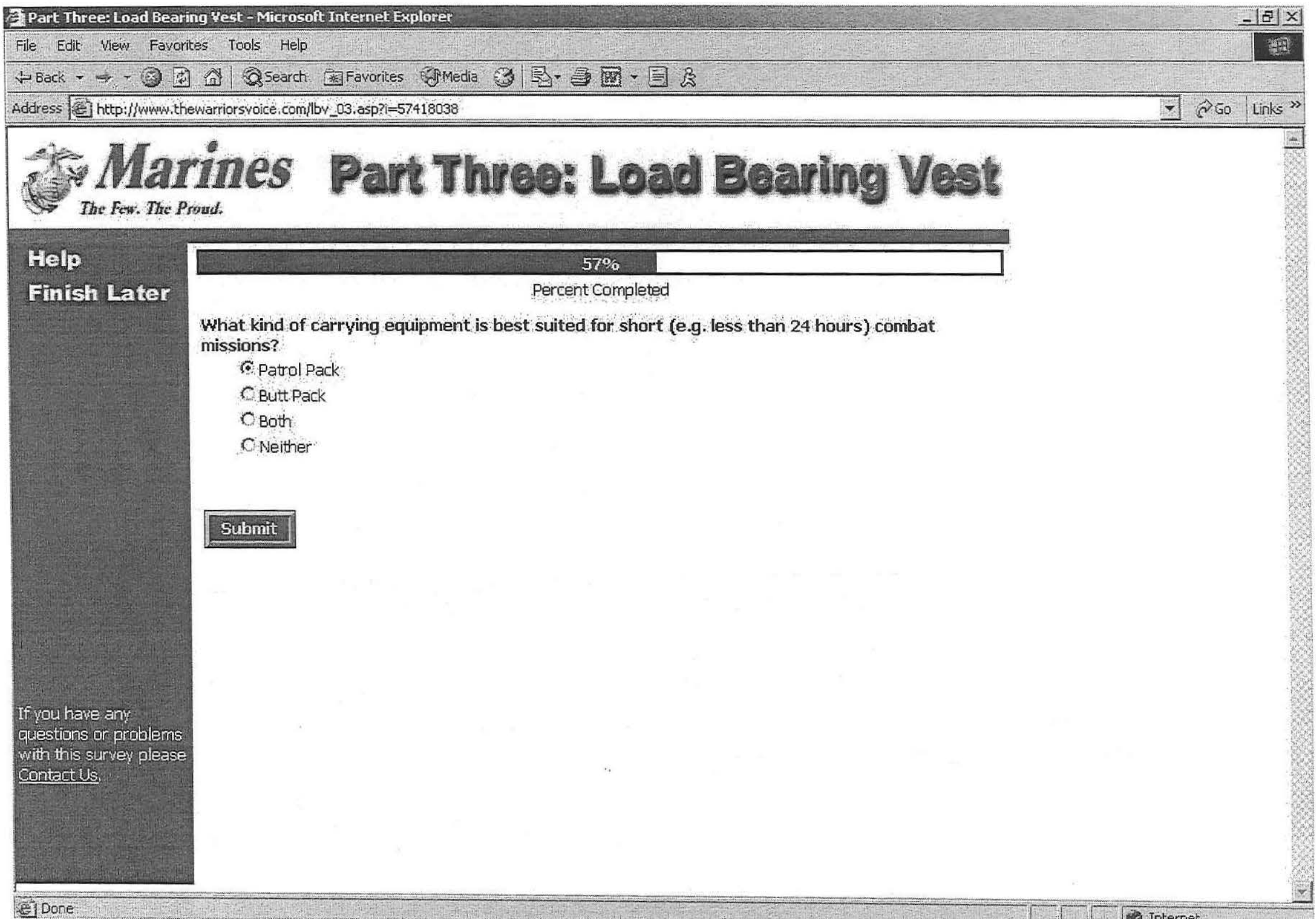

这Done 
File Edit View Favorites Tools Help

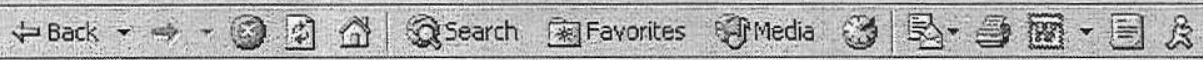

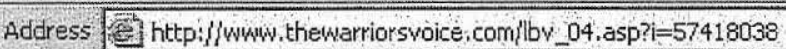

\section{Marines Part Three: Load Bearing Vest}

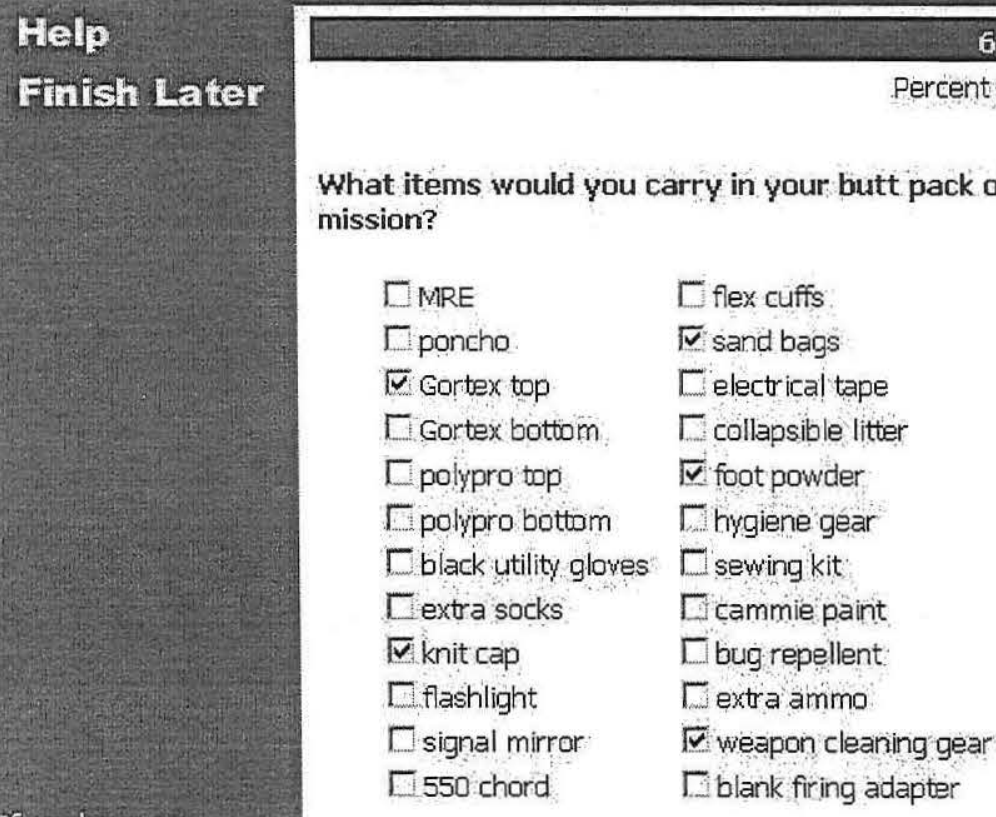

other: $\square$ sample
other:
other:
other: $\square$
other:

uestions or problems

with this sursey please

Contagt Us:

anceres.

$$
\text { submit }
$$


File Edit View Favorites Tools Help tal.

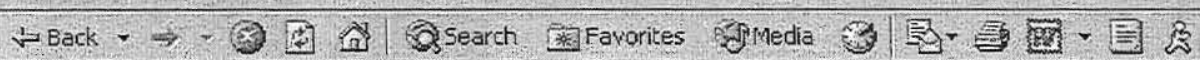

\section{Marines Part Four: Current lissue}

The Faw. The Proud.

\section{Help \\ Finish Later}

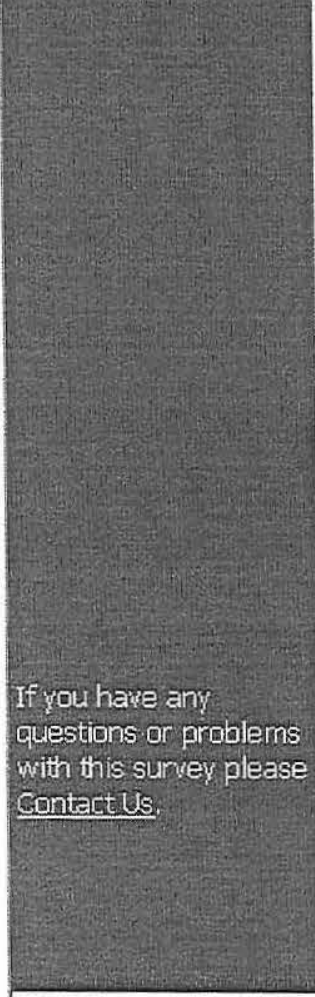

Done

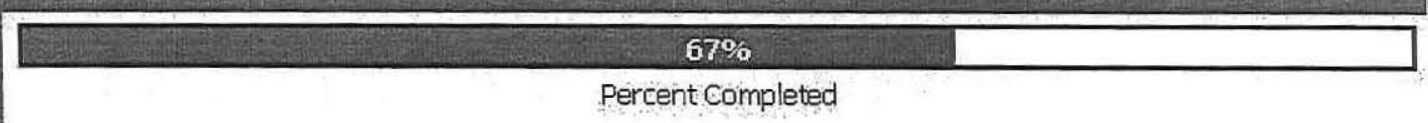

Which Load Carrying System are you using now?

Pack:

OLarge ALICE Pack

C Medium ALICE Pack

SMOLLE I

C MOLLE II

OLwe Vector Pack

\section{Submit}

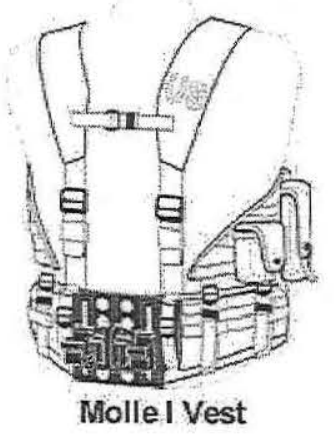

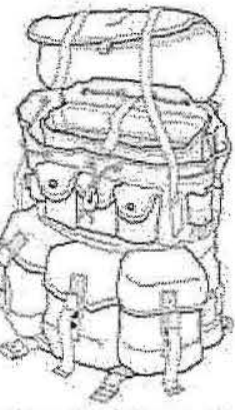

Large ALICE Pack

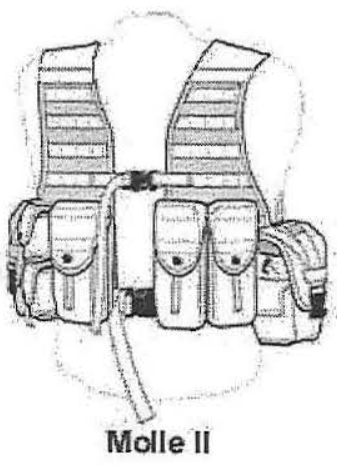

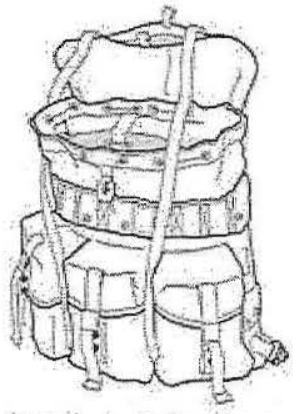

Medium ALICE Pack

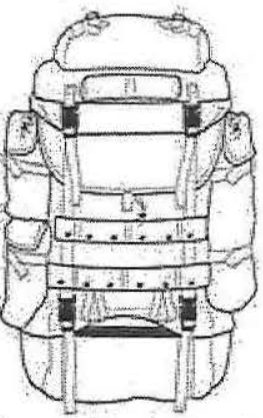

Lowe Vector Pack 
File Edit Yew Favorites Tools Help

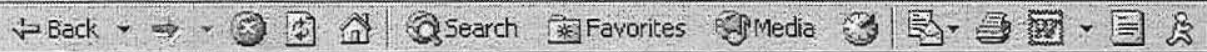

Address hittp://www,thewarriorsyoice.com/current_01a.asp?i $=57418038$

$\Rightarrow$ Cे Go Links

\section{Marines Part Four: Current lssue}

The Few. The Proud.

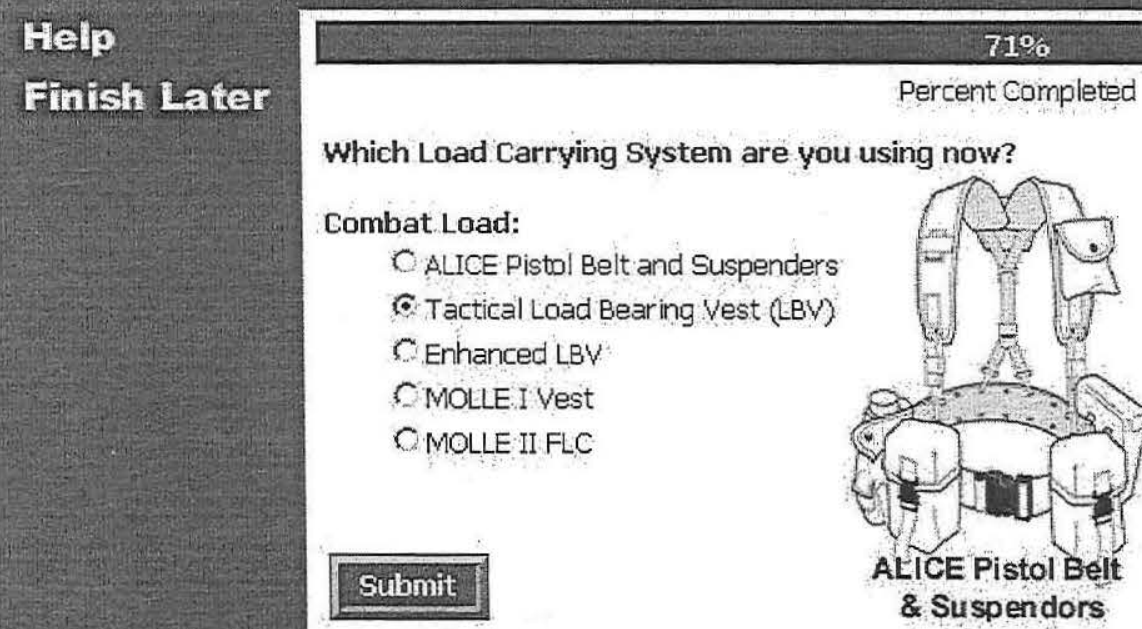

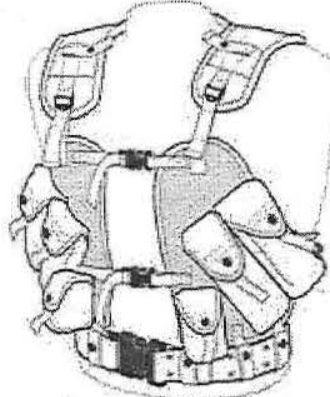

Enhanced LBV

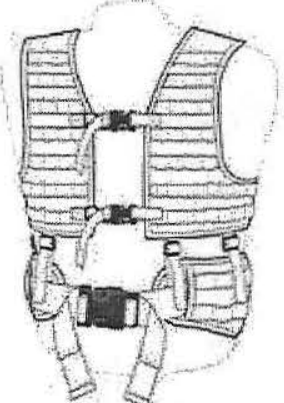

Molle
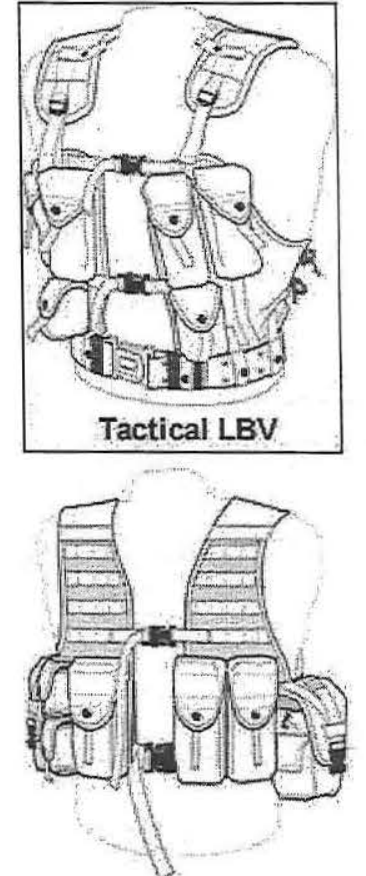

MOLLE II FLC 
File Edit View Favorites Tools Help

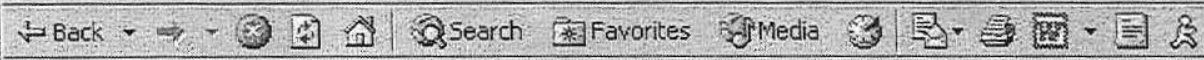

Address 5 hittp://www,thewarriorsyoice:comicurrent_02.asp?i=57418038

Marines Part Four: Current lssue

The Fow. The Proud.

Help

Finish Later

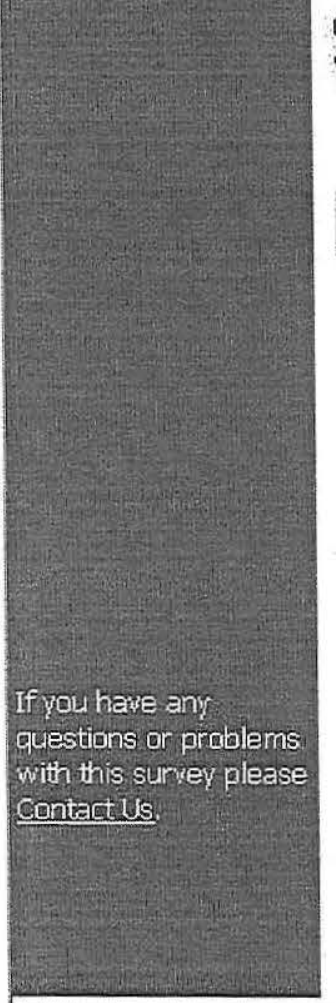

E I Done

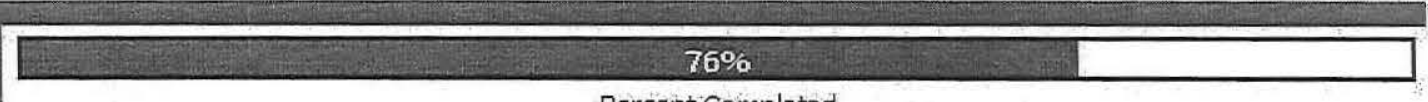

Percent Completed

Overall, how many years of experience do

you have with your currently issued system?

1 years 6 months

Submit 


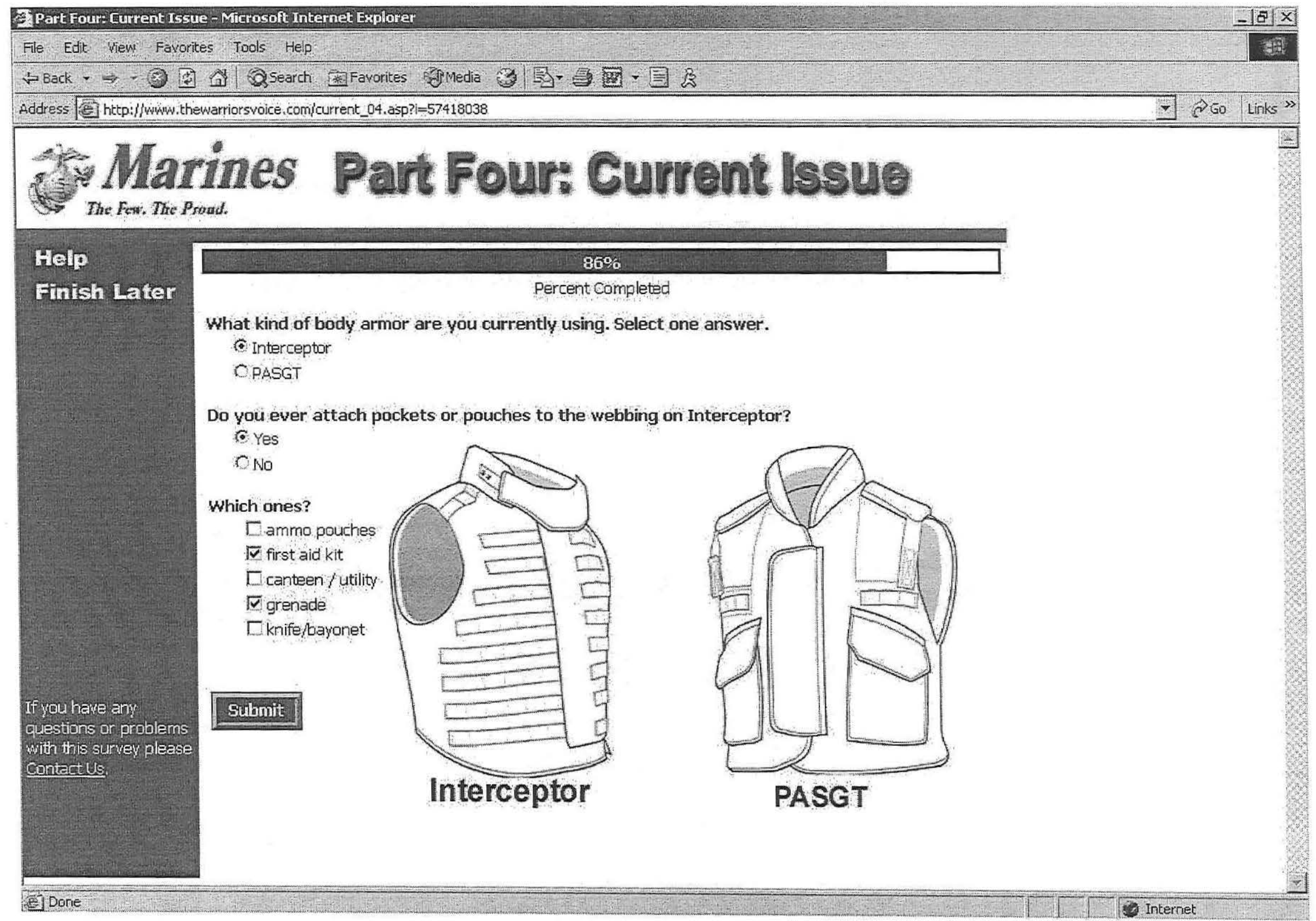




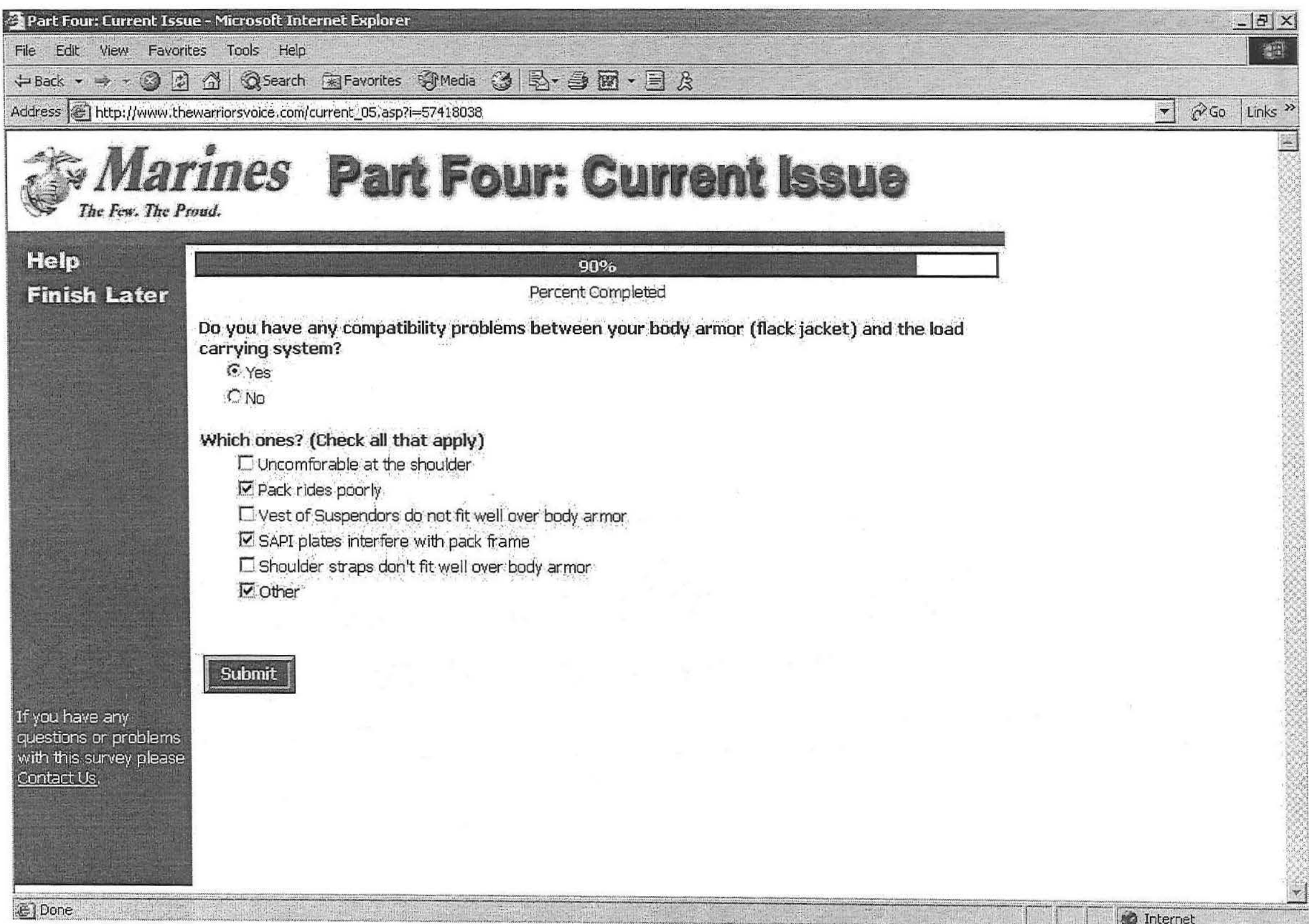


CPart Four: Eurrent Issue-Mitrosoft Internet Explorer _ -

File Edit kent Favorites Tools Help

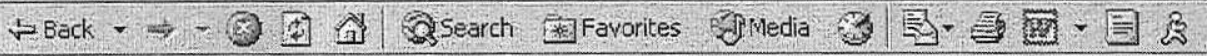

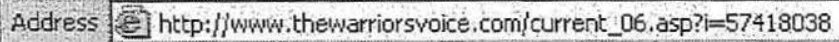

$\rightarrow$ C) EO Links $\gg$ Marines Part Four: Current lssue

The Fow. The Proud.

\section{Help \\ Finish Later \\ Percent Completed \\ Can features of your current system be improved to make it more suitible for Marines? \\ c. Yes \\ No}

What areas need to be addressed? Current system is...

(Check all that apply)

TModularity

IV Main pack size

IMain pack height

TV Main pack width

$\Gamma$ Adjustability

IV Frame height

6 too big C too small

otoo wide 8 not wide enough

IFrame width

Co toolong otooshort

V Improve durability

ПChange layout of system

If you have any

questions or problems

with this sumey please

Submit

gontact Us,

IDone 
File Edit Vient Favorites Tools Help

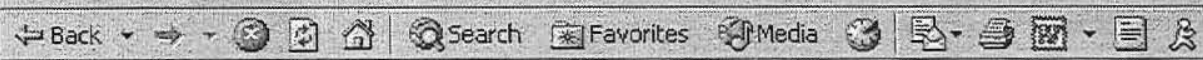

Address en http://wwiw, thewarriorsvoice, com/current_07.asp?i $=57418038$

\section{Marines Part Four: Current lssu@}

The Few. The Proud.

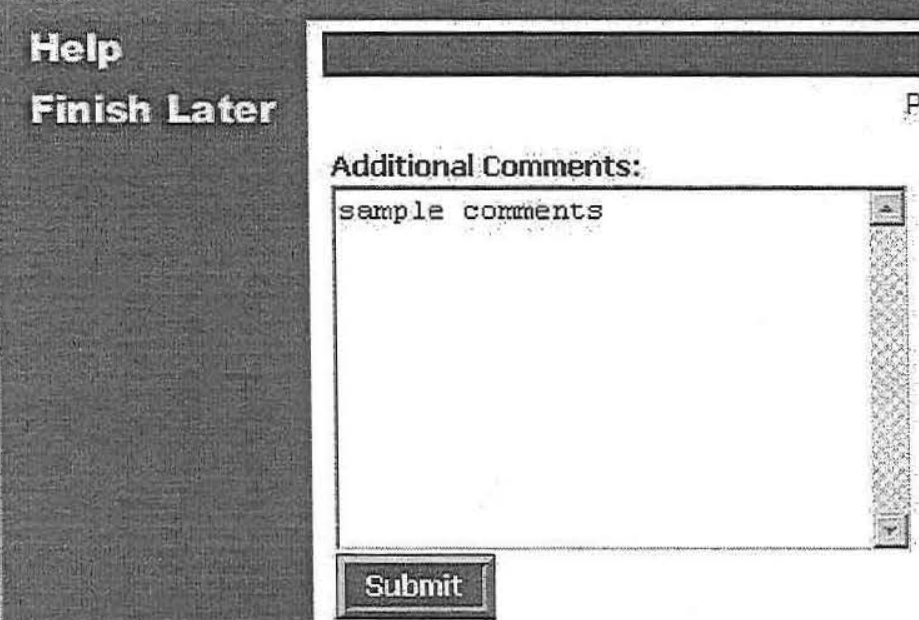

mo

Percent Completed

If you have any

questions or problems

contact Us
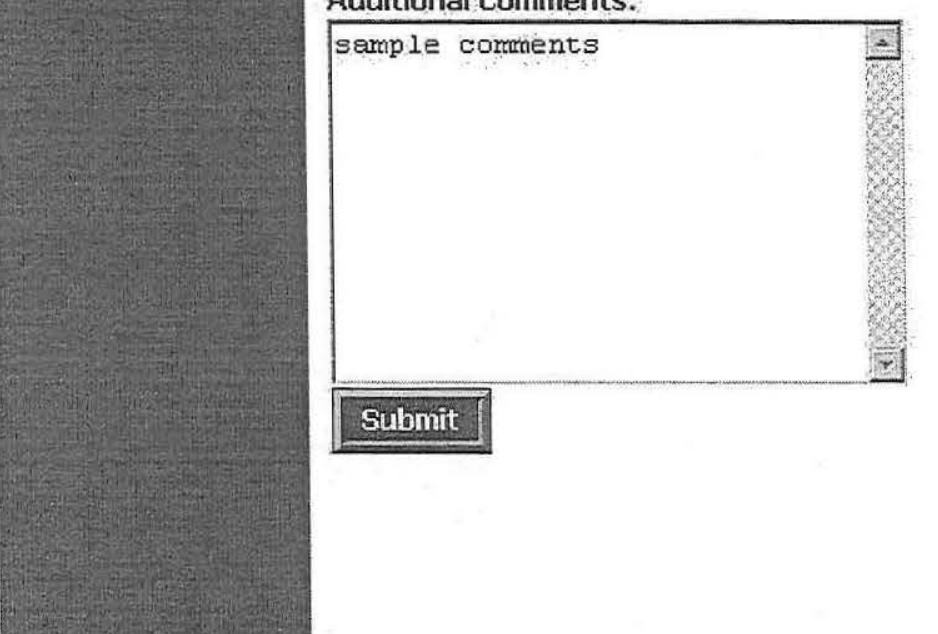

婏Done 


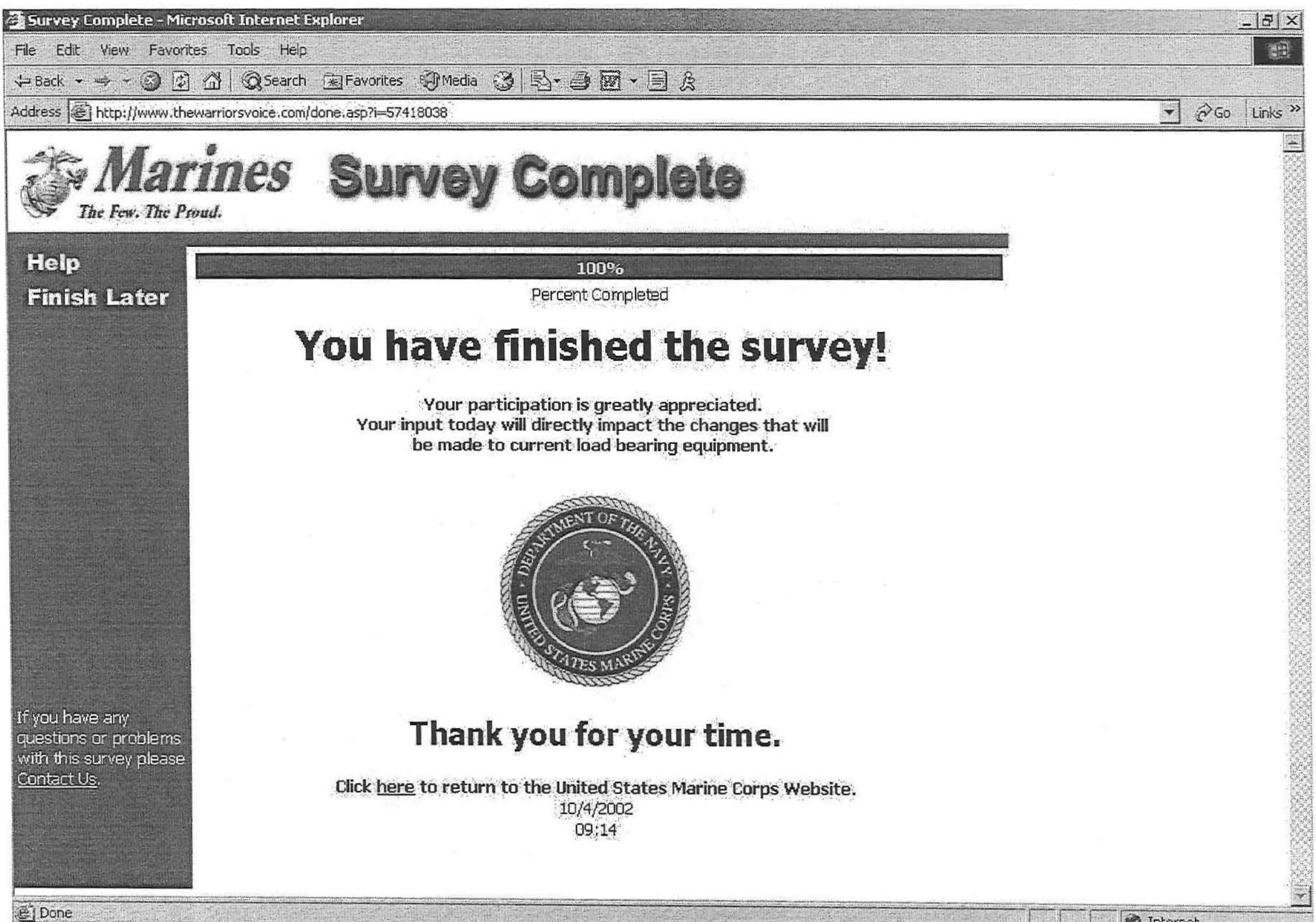

I Done 
File Edit Vien Favorites Tools Help

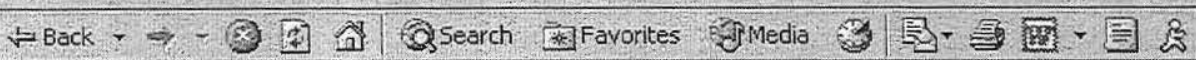

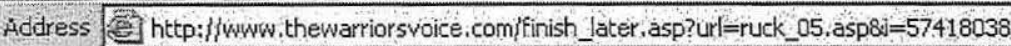

\section{Marines Finish Later}

The Few. The Proud

\section{Help \\ Please select a username and password to login in at a later time:}

Finish Later

Username: $\quad \sqrt{\text { sample }}$
Password:
Confirm Password:

Submit

If you hare any

questions or problems

with this survey alease

gontect Us:

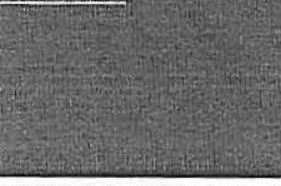

jone 


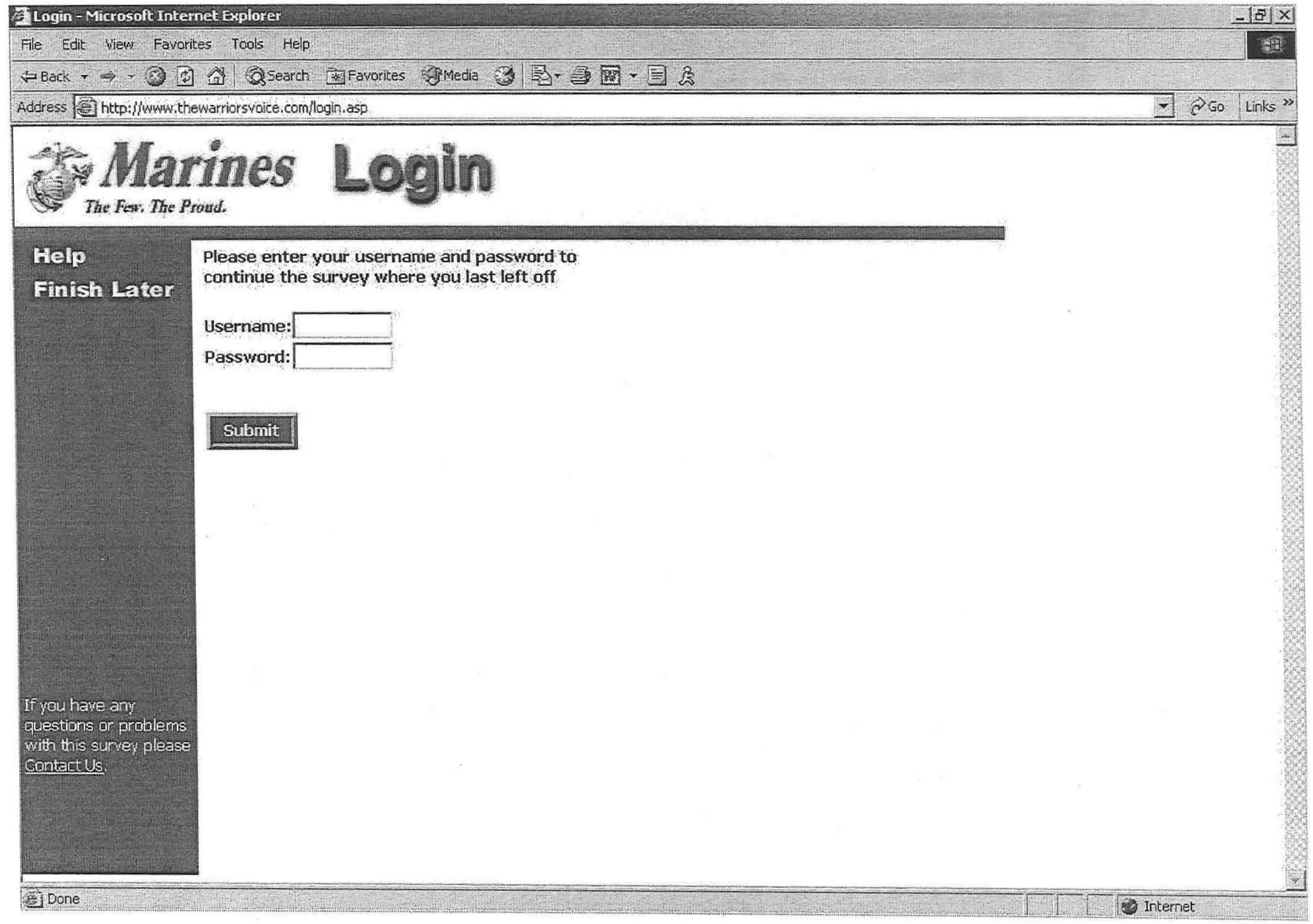


Appendix C.

Script for Focus Groups 
Script for Load Carriage Focus Groups - May 20, 2002 -- Quantico

Introduction: Introduce myself--from Natick Soldier Center. We are looking at ways to create the best load carrying equipment possible.

Sign up sheet: including rank, age, gender, time in service, MOS, current load carriage system that they are using (including both pack and fighting load carrier).

Bring diagram of MOLLE to help facilitate discussion.

We would like to know if they are experiencing any problems or having any issues with their current load carriage system and what suggestions they can make to us about designing a future load carriage system.

I will leave the floor open to them so as not to bias them in any specific direction. However, if they need prompting these are topics/issues that would be good to cover:

\section{Accessibility:}

* Do you have trouble/ problems accessing gear outside of the pack?

* Do you have trouble accessing gear inside your pack?

\section{Adjustability:}

* Is your pack difficult to adjust (why or why not)?

* Does your pack have modular components? Do they work well for you (why or why not)?

* Do you prefer having one large compartment?

\section{Weight/ ltems carried:}

* How many pounds of gear do you normally carry?

- Do you think that your current load carriage system carries your load comfortably? If not do you have suggestions for improvements?

* What do you find is the most difficult weapon to carry?

- What do you find is the most difficult item to carry?

\section{Patrol Pack:}

* When do you use your patrol pack?

* Why do you use your patrol pack? 


\section{Internal vs. Exłernal Frame:}

- Have you used packs with internal frames? If so, did they work well for you (why or why not)?

- Have you used packs with external frames? Is so, did they work well for you (why or why not)?

- Do you have a preference for frame type for your pack?

\section{Drinking System:}

* What system do you currently use?

* Have you had problems with it? If so what were they?

Fighting Load Carrier:

* Which one do they use and what do they like and dislike about it?

\section{Compatibility with Body Armor:}

* Is your current carrying system compatible with your body armor?

\section{Durability:}

- Have you had problems with parts of your pack breaking, tearing etc?

\section{Attach to vehicles:}

- Does your pack attach easily to vehicles and if not how could we improve this? (aircraft, land vehicles and ships etc.)

\section{Perceptions about commercial load carrying systems:}

* Do they have experience with them?

* If yes, do they prefer a specific one and why? 
